\title{
Проблемы и роли структур в восстановлении Афганистана
}

\author{
Адриана Зобрист Галад*
}

Резюме: Интервенция в Афганистане, которая продлилась более десяти лет, не принесла того, на что больше всего надеялись - безопасность для афганского народа и стабилизацию всего региона. Эти процессы ежедневно сталкиваются с вызовами, порожденными сложностью социальных структур Афганистана: его культурой, ценностями, образом жизни, племенными связями, политикой, сетями повстанцев и его историей. Детальное исследование примеров структур, связанных с культурой и политикой, может дать нам общий взгляд на их сложность и на глубоко переплетенные взаимоотношения между разными акторами, причастными к афганскому конфликту. В этом свете мы сможем показать повторяющиеся недостатки либерального способа установления мира в конкретном случае с Афганистаном.

Эти примеры также демонстрируют отличия в ценностях между афганским и западным обществом по отношению к равенству полов, в культурных и политических восприятиях. Возможности разрешения конфликтов на основе традиционных структур-таких, как местные сообщества, племенные или религиозные структуры, или системы традиционных ценностей,--предлагают новые сценарии для исследования реальных стратегий и также их возможного применения.

Верификация представлений об афганской реальности на месте и подготовка к операциям по восстановлению мира могут эффективно улучшить формулировку целей и реализацию действий международного сообщества, и соответственно, улучшить достигаемые результаты. В стране, которая в прошлом всегда успевала отбросить иностранных оккупантов и которая не склонна к принятию диктата извне, шансы на успех нашей миссии могут возрасти, если мы сможем принять то, что либеральные ценности, возможно, не являются универсально применимыми. Прислушиваясь напрямую к голосу афганцев, вовлекая их в процесс восстановления, учитывая реалии афганской жизни в контексте афганских ценностей, - все это дает возможность создать успешную стратегию для восстановления Афганистана.

\section{Введение}

Афганистан является объектом военной и гуманитарной интервенции более десяти лет. «Правильная война»-как президент Барак Обама определил эти действия-имеет нескольких определяющих особенностей. Некоторые исследователи определяют ее как «войну с исламом». ${ }^{1}$ Администрация Обамы категорически разграничивается от таких утверждений и в декабре 2009 года предприняла решительные шаги для разрешения конфликта, заявив о значительном «изменении

* Адриана Зобрист Галад является профессионалом в области разработки программ. Работа, на которой основывается эта статья, была написана для частичного выполнения требований для получения степени магистра современных научных исследований в Женевском центре политики в области безопасности.

1 Steven Simon, "Can the Right War Be Won?," Foreign Affairs 88:4 (July/August 2009): 130 37. 
курса» и изменении официальной терминологии, добавив несколько новых аспектов к процессу: начало переговоров с движением «Талибан» и декларированное намерение вывести боевые части США к 2014 году. Другие исследователи ссылаются на сходство этой войны с войной во Вьетнаме. И критики, и сторонники этой войны признают, что в текущих условиях Афганистан не в состоянии существовать самостоятельно.

Несмотря на уроки истории, международное сообщество было вовлечено в конфликт, выход из которого трудно прогнозировать и в котором трудно определить, что будет являться успехом, и тем более как этого успеха достичь. Одним из ключевых факторов, усугубляющих положение, является спорный характер поставленной цели - создать государственную структуру западного образца в контексте племенного общества, раздираемого незатухающим конфликтом. Настоятельные призывы приоритизировать либеральные ценности-мир, демократию, равенство и экономическую модернизацию-являются вездесущими в докладах и политических речах, касающихся западных миссий в Афганистане. Слабые места этих миссий в основном связаны с потерями среди гражданских лиц и допущенными оплошностями, которые сильно задевают культурную и религиозную чувствительность афганского народа.

В социальной структуре Афганистана доминирует множество слоев этнического, племенного, кланового, семейного или каум характера. ${ }^{2}$ Мое первоначальное намерение - анализировать эти разнообразные структуры (политические, культурные, племенные, экономические, региональные, военные, религиозные и т.д.), было бы слишком сложно осуществить, и на это потребовалась бы целая жизнь. Поэтому основное внимание в этой статье будет направлено на репрезентативные примеры культурных и политических структур и на их роль в жизни Афганистана. Однако, ссылки на другие существующие структуры и факторы будут оставаться нераздельной частью исследования.

Значение этих структур, органически присущих афганскому обществу, не учтено и не отражено в достаточной степени в стратегиях, целях или в текущей политике нынешних миссий. А если и учитывается, то используемые подходы реализуются недостаточно хорошо. Невежество, пренебрежение или неправильное понимание в отношении этих структур и их жизненно важной роли в процессах восстановления и развития являются причиной относительно неудовлетворительного уровня достижения положительных результатов в сравнении с количеством финансовых, военных, человеческих ресурсов и усилий, затраченных в Афганистане за последние десять лет. Слабость и (дис)функциональность, наблюдаемые в основном в существующих политических структурах, поддерживаемых международным сообществом, показывают, что либеральные западные ценности не являются работоспособными целями во всех случаях и при всех обстоятельствах. Социальная структура Афганистана устояла внешнему влиянию в течении последних

2 Каум - это социальная структура, основанная на связях солидарности, которые могут выходить за этнические или племенные границы. 
трех десятилетий - сперва в годы советской оккупации, а затем и во время длительного периода правления талибов. Сейчас она подвергается испытанию процессом создания в Афганистане систем и структур, не вполне подходящих или не совсем совместимых с афганскими ценностями и традиционным афганским образом жизни. Ситуация в Афганистане такова, что в любом государстве, при любой системе ценностей, на восстановление понадобилось бы немало времени. Более того, перед Афганистаном стоят множество новых проблем. Внедряются новые идеи и новые структуры, и способность афганского общества полностью абсорбировать и интегрировать их оказывается ограниченной. Такие изменения при благоприятных обстоятельствах было бы разумно осуществлять в течении длительного процесса, но от Афганистана требуют подвергнуться существенной трансформации за относительно короткий период времени.

Первая часть этого эссе будет посвящена исследованию двух культурных аспектов, указывающих на важность структур, которые характеризуют афганское общество-моральный кодекс поведения, Пуштунвали, и значение чадры или бурки,一как двух комплексных элементов, имеющих свои корни в традиционной культуре региона. Мы покажем, каким вызовом для системы западных ценностей являются эти два примера, как они влияют на образ жизни и насколько существенно их значение на формирование ценностной системы афганцев. И что более важно, внимание будет направлено на интерпретацию и на общий подход к этим структурам при наблюдении их как изнутри, так и извне афганского общества. Вторая часть работы сфокусирована на двух примерах, представляющих политическую организацию и текущую политическую структуру. Закрепленный в Конституции Афганистана пост Президента является очень влиятельным в юридическом смысле. В последовательности примеров, демонстрирующих, насколько слаба в действительности позиция Президента, будут показаны основы и недостатки текущей политической архитектуры. Что касается движения «Талибан», в эссе будет рассмотрен вопрос, является ли его способность эффективно использовать поддержку населения, основанную на традиционном моральном кодексе и на предоставлении услуг, которые центральное правительство не в состоянии обеспечить, признаком его «воскресения» и возможного будущего успеха. В третьей части статьи будет рассмотрена связь между вышеуказанными примерами и, основываясь на конкретной ситуации в афганском контексте, будет сделана попытка обрисовать сложность этих проблем в ежедневной жизни, а также исследовать их связь с примерами, рассмотренными в предыдущих частях.

На основании примеров этих глубоко укоренившихся схем и взаимоотношений, я продемонстрирую их роль и также попытаюсь определить, насколько они совместимы (или несовместимы) с основными ценностями и практиками, являющимися основополагающими для международной интервенции в Афганистане. В исследовании поднимается ряд вопросов: у нас не хватает знаний об этих структуpax и местных ценностях, или наши собственные ценности мешают нам их применять? Может ли более глубокое понимание афганской культуры и политических структур-и в результате, лучшая подготовка и последующее применение этих 
знаний в ходе миссии и процесса восстановления,-быть ключом к успешной долгосрочной стратегии достижения стабильного мира? Действительно ли эти структуры дают вариант реалистической и устойчивой политической модели в Афганистане, которая подходит афганцам? Что мешает нам признать их важность или использовать их? Не та ли это политическая программа, которую обязано защищать и продвигать международное сообщество, чтобы получать общественную поддержку и финансирование этой миссии в соответствующих странах? Или мы просто игнорируем их из-за более глубоких философских причин, возможно просто по причине солипсизма? Какие факторы мешают афганцам отстаивать свое право иметь более влиятельный голос в определении архитектуры их собственного государства?

Чтобы понять всю глубину комплексных проблем, которые имеют отношение к теме этого анализа, их надо рассматривать в региональных измерениях и в региональном контексте. Однако, внимание в этой статье не будет направлено на развитие ситуации в Пакистане или Иране и ниже эти взаимосвязи не будут рассматриваться в деталях. В процессе этого критического и сравнительного анализа возникают другие проблемы, которые ведут это исследование к поднятию более фундаментальных вопросов относительно качества человеческих ресурсов на всех уровнях, развернутых в Афганистане, их подготовки, физических и психологических способностях, необходимых для такой миссии. Однако исчерпывающий ответ на эти вопросы является предметом дальнейших исследований. Как показывают последние события, месяцы интенсивных переговоров, тысячи человеческих жизней, потерянных в ходе конфликта, миллиарды, потраченные на процесс восстановления, легко и в один день могут быть перечеркнуты неподобающим поведением, неуважением или пренебрежением к высоко почитаемым национальным ценностям и привести к росту враждебности местного населения. Все более ясно становится, что детальное знание страны не только в географическом смысле является обязательным предварительным условием любой военной или гуманитарной операции такого масштаба, как та, что сейчас проводится в Афганистане. В итоге, эта статья закончится рассмотрением дальнейших последствий этих идей и будут предложены рекомендации с точки зрения практического работника.

\section{Структуры, связанные с культурой}

\section{Афганистан: простой и сложный}

В соответствии с основной целью этой статьи важно дефинировать понятия структура и культура, на которых основывается первая часть этой работы, с тем, чтобы внести большую ясность в сущность вопроса. Аргументы и примеры, использованные в процессе исследования или при формулировке заключений, также следует интерпретировать в контексте этих дефиниций. В антропологии структуралистский подход используется все более широко. Он был популяризирован Клодом Леви-Строссом, который считал, что «не уникальность социумов, а разли- 
чия между ними являются предметом структурной антропологии». ${ }^{3}$ Эта концепция применялась при исследовании языка, средств массовой информации, религии и культуры. В отличии от Леви-Стросса, Клиффорд Гирц рассматривал антропологию «не как экспериментальную науку, которая ищет законы, а как интерпретативную науку в поисках сетей значений». ${ }^{4}$ И тот, и другой, однако, были согласны с тем, что естественный порядок поведения людей и «сеть значений», которые и составляют культуру, не могут быть отделены от человека и его намерений в процессе социальных взаимодействий. Согласно трудам Дюркхайма, «схемы человеческого поведения формируют установившиеся структуры; они являются социальными фактами, которые определяют действительность вне жизни и восприятий отдельных личностей». ${ }^{5}$

Теория Леви-Стросса и Гидденса содержит идею, что «личность и общество составляют одну двойственную сущность. Функциональный подход рассматривает структуры как ограничивающие и в то же самое время позволяющие следующее: устанавливая ограничения в действиях, они являются той средой, которая дает возможность индивиду влиять на его окружение». ${ }^{6}$ Гидденс определяет структуры как «правила и ресурсы, применяемые индивидами при производстве и воспроизводстве социальных действий». ${ }^{7}$ Концепция структуры сейчас часто является сущностной основой практически любого исследовательского подхода или открытия в науке, философии или искусстве. Описание структуры неявным образом предоставляет отчет о том, из чего составлена система - множества взаимосвязанных компонентов. Поэтому структуры наблюдаются в иерархии или в историческом опыте, они присутствуют как сеть действий в рамках племени или семьи, в конфигурации связей между суб-племенами, политическими акторами, между двумя полами, или между иностранцами - между всеми теми компонентами, которые в настоящий момент связаны с афганским контекстом.

Как было сказано выше, люди и их социальные конструкты являются главными объектами и акторами при создании структур. В то же время, действия людей в процессе создания структурных сетей находятся под влиянием не только их поведения, но и под влиянием уже существующих структур. Значение этих структур видно, к примеру, при реализации возможности сделать свободный выбор и действовать независимо. Как структуры, однако, могут рассматриваться и такие факторы, определяющие действия, как социальный класс, религия, пол, обычаи, этническая принадлежность и т.д. Структуры следует рассматривать скорее как нейронную систему внутри общества или страны, чем как их скелет. Причиной

\footnotetext{
Tom Ingold, ed., Companion Encyclopedia of Anthropology (London: Routledge, 1994), 370. Там же, 37.

John J. Macionis and Ken Plummer, Sociology: A Global Introduction (Upper Saddle River, NJ: Pearson Education, 2010), 125.

6 Scott A. Appelrouth and Laura Desfor Edles, Classical and Contemporary Theory, $2^{\text {nd }}$ Edition (Thousand Oaks, CA: Pine Forge Press, 2012), 719.

7 Anthony Giddens, The Constitution of Society (Berkeley: University of California Press, 1984), 19.
} 
для этого является тот факт, что структуры не только обладают определенными органическими качествами и гибкостью, но и являются объектом постоянного метаморфоза. У них есть способность-как и у органической материи-отражать и реагировать на значимые внешние и внутренние факторы (например, инвазия или эмиграция, изменение технологии или режима). Этот процесс изменения и эволюция не отличается скоростью, но после сформирования новой структуры ее влияние прогрессивно растет.

Нетрудно объяснить, почему исследования, связанные с концепциями культуры, в политических науках, анализе безопасности или при сравнительных политических исследованиях встречаются относительно редко. Во-первых, культура не является концепцией, которая обычно изучается политологами или аналитиками по безопасности. Причиной может быть то, что культурологический подход усложняет проблемы, которые основываются на реальных фактах; попросту говоря, культуру трудно учитывать, потому что это не точная наука. Во вторых, попытка использовать такие неопределимые факторы как поведение, социальные стремления и культурные модели в качестве доказательств может испортить впечатление того, что применяется достаточно научный подход. В третьих, культурологический анализ также поднимает множество проблем и вопросов, на которые нельзя ответить в рамках политических наук или исследований по безопасности (хотя на них более адекватно могли бы ответить другие социальные науки).

Но что понимать под термином культура, который мы используем? Культура, часто используемая в социологии и антропологии как основополагающее понятие, дефинировалась многими способами, трактовавшими «культуру как социальную организацию, основные ценности, особые убеждения, социальные действия или образ жизни», с небольшими вариациями. ${ }^{8}$ Более современные анализы, однако, начинаются с определения Гирца культуры как «исторически наследуемой модели значений, воплощаемой в символах, системе унаследованных понятий, выражаемых в символических формах, с помощью которых люди общаются, увековечивают и развивают свои знания о жизни и свое отношение к ней». ${ }^{9} \mathrm{C}$ этой точки зрения подчеркивается характеристика культуры как совокупности публичных, общих понятий; «поведение, институты и социальные структуры понимаются не как собственно культура, а как определенные культурой феномены». ${ }^{10}$

И в афганском контексте особенно, многие культурные и политически аспекты текущей ситуации нельзя понять без ссылок на историю, географию и религию в

8 Alfred Louis Kroeber and Clyde Kluckholm, "Culture: A Critical Review of Concepts and Definitions," Papers of the Peabody Museum of American Archaeology and Ethnology 47:1 (1952).

9 Clifford Geertz, "Religion," в The Interpretation of Cultures (New York: Basic Books, 1973), 89.

10 Melford E. Spiro, "Some Reflections on Cultural Determinism and Relativism with Special Reference to Emotion and Reason," в Culture Theory: Essays on Mind, Self, and Emotion, под ред. Richard A. Shweder, Robert A. LeVine (Cambridge, UK: Cambridge University Press, 1984), 323-46. 
терминах повседневной жизни людей. Территория, которую сейчас мы называем Афганистаном, занимает центральное положение в пространстве, где соприкасались четыре великие цивилизации. Несмотря на эту неоднородность и разнообразие, несмотря на последствия конфликтов последних десятилетий и изгнанничество, афганцы продолжают придерживаться традиционных ценностей и обычаев, что отличают их от их соседей, и они продолжают придавать существенное значение этническому разнообразию и региональным различиям. Несмотря на это, сущность и корни их культуры остаются сильными в их сознании и традициях. Может, они и изменились каким-то образом со временем, но они остаются идентифицируемыми. Несколько ученых, которые проводили свои исследования в Афганистане в течении последних десятилетий, считают, что это большое разнообразие, очевидное повсюду вокруг Афганистана, добавляет ценности и богатства их культуре и делает их общество весьма сложным. Множество групп населения придерживаются различных духовных убеждений: там живут сунниты, шииты, исмаилиты, сикхи, индуисты и иудеи. Большое число национальностей так же приводит к этническому соперничеству, наиболее заметному между доминирующими пуштунами и таджиками, хотя конфликты между пуштунами и хазарейцами, и фракционализм среди самих пуштунов являются характерной чертой афганской реальности, реальности еще более усложняемой присутствием множества других этнических групп: узбеков, туркменов, аймаков, белуджи, брахуисов, пашаисов, нуристанцев и т.д. Несмотря на высокий уровень этнического многообразия среди населения Афганистана, существует мощный фактор, объединяющий афганцев. «Рассмотрение афганской истории подтверждает наличие повторяющейся модели чередующихся периодов разделения и объединения. Афганцы могут с упоением ссориться между собой, но они встают вместе и защищают свою гордость и право быть афганцами, когда им угрожают захватчики. Чувство национальной идентичности на самом деле существует, несмотря на элементы раскола». ${ }^{11}$ Но как нам понимать значение выражения «быть культурным» в обществе, где 70 процентов населения неграмотно? Как нам измерить уровень культуры, если в афганской реальности это определенно не означает быть хорошо образованным или начитанным? В Афганистане высоко цениться мудрость, не связанная с формальным образованием, и это находит отражение в практике местного обычного права. В этом конкретном случае личности, «которые соблюдают правила общепринятого поведения и следуют предписаниям этикета» пользуются большим уважением. Более того, вследствие ярких традиций устной коммуникации, многие неграмотные люди хорошо осознают свое культурное наследие. ${ }^{12}$

Рассмотрение вблизи и понимание структур в культурной и политической системе Афганистана может помочь нам нарисовать сложную картину функционирования (modus operandi) афганского общества. Более того, такое наблюдение может

11 Nancy Hatch Dupree, "Cultural Heritage and National Identity in Afghanistan," Third World Quarterly 23:5 (2002): 977.

12 Там же, 978. 
подсказать, как подойти к миссии, которую пришли исполнить в Афганистане западные страны. История показывает, что внедрение современных, западных ценностей в афганское общество не было успешным, несмотря на то, что в некоторых случаях инициатива исходила из их же собственного легитимного политического руководства (как будет показано ниже на примере бурки). Насколько велики наши шансы, как иностранцев, в такой попытке? Нам нужно упорно работать, чтобы признать и соответственно учитывать отличия между нашими ценностями и ценностями афганского народа - отличия, являющиеся продуктом другой истории, реакциями на другие обстоятельства, и выражением иначе структурированной системы стремлений.

\section{Пуштунвали: моральный кодекс, пришедший из древности}

Уинстон Черчилль определенно не был очарован моральным кодексом пуштунов, потому что он описал его следующими словами: «Их этическая система, которая почитает предательство и насилие как добродетели, а не как пороки ... непостижима для логического ума». Это мнение остается весьма широко распространенным и символизирует один из самых значимых вызовов, с которым мы сталкиваемся в ходе нашей миссии в Афганистане и который отражается на нашем складе ума. «Независимо от того, понятна или непонятна нам [местная] культура, мы живем в мире, который заставляет нас принимать решения». ${ }^{13}$ Другим вызовом для исследователя, стратега, политика и просто солдата или гуманитарного работника является выбор между множественными культурными реалиями - выбор между тем, следовать ли привычной системе ценностей, в которой мы были воспитаны, или принимать те ценности, которые окружают нас в настоящий момент.

Этот афганский моральный кодекс, известный как Пуштунвали, может выглядеть в глазах западного человека устаревшим, странным или попросту ошибочным. Но для афганца защита своей чести (uззаm) находится выше любых других соображений, включая приобретение денег или собственности. Это пьедестал, на котором базируется весь социальный статус. В афганском обществе наиболее важным социальным институтом считается семья, в отличии от Запада, где объектом наивысшего интереса и права является личность. Как писал один ученый: «Честь индивида, гордость от независимости, которая проистекает от расчета только на собственные силы, выполнение семейных обязанностей, уважение к старшим, уважение к женщинам, лояльность к коллегам и друзьям, терпимость к другим, прямота, отвращение к фанатизму и неприязнь к хвастовству - вот культурные качества, присущие большинству афганцев». ${ }^{14}$ Пуштунвали - означает буквально «путь пуштунов» - является чем-то намного большим, чем просто система обычного права. Это всеобъемлющий кодекс поведения и образ жизни. Большинство афганцев живет в соответствии с каким-либо вариантом этого ко-

13 Richard M. Merelman, Partial Vision: Culture and Politics in Britain, Canada and the United States (Madison: University of Wisconsin Press, 1991), 232.

14 Dupree, "Cultural Heritage and National Identity in Afghanistan," 978. 
декса, хотя не-пуштуны не обязательно означают свой моральный кодекс этим наименованием. Однако, афганское общество остается системой, основанной на понятии о чести, в которой наличие чести гарантирует членство в этом обществе и движет всеми социальными взаимодействиями. «Пуштун без чести не может больше быть пуштуном, и у него не будет прав, защиты и поддержки со стороны общности». ${ }^{15}$ Хотя другие этнические группы не применяют некоторые положения Пуштунвали, большинство принципов остаются теми же. В то же время этот кодекс «подчеркивает автономию и равенство политических прав в мире равных. Это невозможно осуществить в обществе с классовой структурой или там, где власть запрещает такие институты как кровная месть, или требует платить налоги». ${ }^{16}$ Пуштунвали не есть анархия, а скорее «альтернативная форма социальной организации с хорошо развитым механизмом разрешения конфликтов». ${ }^{17}$ И это достигается без судов, адвокатов, полиции, тюрем или палачей посредством джирси, квази-правового процесса, разрешающего большинство их [афганцев] проблем.

Исламские религиозные практики и законы, похоже, накладываются на гораздо более старый племенной социальный кодекс. Это две отличающиеся системы, и хотя они сосуществуют в относительной гармонии, Пуштунвали имеет более глубокие корни. Основными столпами этого основанного на понятии о чести общества являются понятия рыцарства, храбрости или отваги (каланг или нанг); гостеприимства (мелмастия); четкого разграничения между полами (пурда или намус); и совета (джирга). ${ }^{18}$

«Рыцарство определяется двумя системами нормативных практик: благородными действиями в бою и защитой собственной чести. Благородное поведение в бою содержит правила, касающиеся относительно необходимых боевых умений, включает храбрость и определяет, на кого можно нападать, - к примеру, нельзя

15 Kakar Palwasha, "Tribal Law of Pashtunwali and Women's Legislative Authority" (Harvard Islamic Legal Studies Program, 2005), 3.

16 Thomas J. Barfield, "Weapons of the Not so Weak in Afghanistan: Pashtun Agrarian Structure and Tribal Organization for Times of War and Peace," paper for the for Agrarian Studies Colloquium Series, "Hinterlands, Frontiers, Cities and States: Transactions and Identities," held at Yale University (23 February 2007), 11.

17 Thomas H. Johnson and M. Chris Mason, "No Sign Until the Burst of Fire," International Security 32:4 (2008): 61.

18 Многие ученые писали о важности этих элементов в афганском обществе. Смотри Nancy Louis Dupree, "Cultural Heritage and National Identity in Afghanistan"; Thomas Barfield, Afghanistan: A Cultural and Political History (Princeton, NJ: Princeton University Press, 2010); Barfield, "Afghanistan's Ethnic Puzzle: Decentralizing Power Before the U.S: Withdrawal," Foreign Affairs 90:5 (2011); Peter Tomsen, Wars on Afghanistan: Messianic Terrorism, Tribal Conflicts, and the Failure of Great Powers (New York: Public Affairs, 2011); Frederik Barth, ed., Ethnic Groups and Boundaries: The Social Organization of Culture Difference (Boston: Little, Brown, 1969); и Pierre Centlivres, Micheline Centlivres-Demont, "Afghan Women in the Turmoil of Modernity," в Afghanistan on the Threshold of the $21^{\text {st }}$ Century: Three Essays on Culture and Society (Princeton, NJ: Markus Wiener Publishers, 2010). 
нападать на мирных жителей, и как распределять военную добычу». ${ }^{19}$ Защита чести требует ответа на каждую обиду или унижение, нанесенные другим. Такая защита называется бадал (справедливость или месть) и осуществляется между затронутыми сторонами, если возмездие не является чрезмерным, в случае чего вмешивается совет. Бадал не имеет ограничений по времени и пространстведействует, пока не будет принято адекватное решение,- -и может передаваться от поколения к поколению. «В случаях прелюбодеяния или убийства честь потерпевшего, его семьи и родственников может быть восстановлена только крайним актом убийства обидчика». ${ }^{20}$ Эта концепция не встречается в правовой системе западных обществ, и мы на практике часто пренебрегаем ее существованием в афганском обществе, как будет показано далее на примере программ защиты равноправия полов.

Мелмастия (гостеприимство) в отношении как чужих, так и друзей укрепляет честь; акты проявления гостеприимства расширяют социальную сеть индивидуума, что увеличивает его авторитет. «Гостеприимство включает нанавати - защиту своих гостей - буквально означает войти в безопасность дома», и распространяется на любого, кто взывает к защите по законам гостеприимства, включая врагов. ${ }^{21}$ Очевидно, это создает сложности для воюющих, когда силы противника требуют приюта от местного населения. Такая практика широко использовалась талибами или членами Аль-Каиды и часто неправильно понимается международным сообществом как признак местной поддержки движения «Талибан».

Границы между полами (намус и пурда) разделяют физическое пространство, занимаемое мужчинами и женщинами. Они варьируют между социальными классами в вопросных группах. Каждая группа имеет свое личное пространство, которое должно соблюдаться лицами противоположного пола, даже если они являются посетителями или чужими. Какар Палваша отмечает: «Уровень разделения разнится от наиболее строгого в каланг обществах, через среднюю степень, что наблюдается среди нанг населения, и до наиболее либерального в Кучи общинах». ${ }^{22}$ Остается открытым вопрос, в какой степени мы учитываем и считаемся с этой сегрегацией, когда работаем с афганцами в международной рабочей среде, и каким вызовом этот вопрос является для людей Запада, у которых очень мало следов сегрегации полов в их обществах: ни в семье, ни в системе образования, ни в рабочей среде. Что нам делать в реальных ситуациях, связанных с пурда в Афганистане, если в западных обществах равенство полов является высоко уважаемой ценностью, которая закреплена на социальном, политическом и правовом уровне?

Джирга (совет) является многовековым институтом. Не существует единого понимания о его функционировании среди членов общества пуштунов. Традици-

19 Palwasha, "Tribal Law of Pashtunwali."

20 Nabi Mistdaq, "Historic Perspective on Afghanistan, its People and Culture," panel presentation in Rayburn House Office Building, Washington D.C., 25 March 2009.

21 Frederik Barth, "Pathan Identity and its Maintenance," в Ethnic Groups and Boundaries: The Social Organization of Culture Difference, под ред. Barth (Boston: Little, Brown, 1969), 120.

22 Palwasha, "Tribal Law of Pashtunwali," 5. 
онно это собрание людей, принимающих решения в племени, деревне, регионе или социальной группе, которые приходят к консенсусу относительно последующих действий, а не следуют логике отдельного индивидуума. Этот совет подобен исламской Шуре. Имя часто используется для обозначения «советов, составленных из уважаемых членов общества, обычно старейших, принадлежащих к землевладельческой элите в калангских сообществах, признанных людей чести, собиравшихся для принятия решений». ${ }^{23}$ Решения джсири, этой афганской версии афинской демократии, «являются окончательными и единодушными, так как никто не может быть обвязан решением, которого он не принимает. Высшим добром являются честность и коллективная справедливость, а не наказание индивидуального нарушителя правил, как это принято на Западе, концепция, которая является чуждой для пуштунов». ${ }^{24}$ Традиционно джирга открыт для каждого члена общины, но присутствие признанных лидеров обязательно. На практике, в литературе упоминается об очень малом количестве случаев участия женщин и молодых членов групп в работе джирги. Лойя джирга, созданная в 2002 году под эгидой $\mathrm{OOH} \mathrm{в} \mathrm{результате} \mathrm{Боннского} \mathrm{соглашения,} \mathrm{включает} \mathrm{и} \mathrm{другие} \mathrm{этнические} \mathrm{группы,}$ кроме пуштунов, и имеет квоту для представителей-женщин. Она является признаком безусловно демократического процесса и представляет собой критически важную модернизацию этого древнего и традиционного института принятия решений. С другой стороны, отсутствие представителей политических партий в новом парламенте на фоне большого числа кандидатов на выборах и соперничество между парламентариями подрывает возможность введения системы сдержек и балансов, и обеспечивает афганскому правительству благоприятные условия для поиска подхода к индивидуальным членам парламента для поддержки доминирования правительства над парламентом, в основном посредством коррупции и взяток (которые остаются самыми большими проблемами, стоящими перед афганским обществом, сразу после проблем безопасности).

Чадра и бурка ${ }^{25}$

Многие ученые, репортеры или комментаторы часто говорят о способности афганского общества сопротивляться иностранным нашествиям и иностранному управлению, приводя в пример британскую и советскую оккупацию в прошлом. Пример структуры, связанной с культурой, которую я решила представить, пойдет чуточку дальше. Он будет не только историческим обзором отношения к бурке и чадре в прошлом столетии, но и продемонстрирует, что сопротивление иностранному владычеству или иностранным идеям не является единственной характеристикой афганского общества. В действительности глубоко окопавшееся сопротив-

23 Akbar Ahmed, Millennium and Charisma Among Pathans. A Critical Essay in Social Anthropology (London: Routledge and Kegan Paul, 1976), 83.

24 Johnson and Mason, "No Sign," 61.

25 Бурка (на арабском) или афганская чадра означают одежду, которая покрывает все тело женщины с головы до пяток, с прорезями для глаз. 
ление любым современным элементам, которые не синхронизированы с остальными традиционными структурами афганской культуры, является повторяющейся моделью в обществе, часто являющееся прямым отрицанием власти афганского руководства или других законных лидеров, которые поддерживают такие идеи или которые пробуют ввести такие новые элементы. Если подавляющее большинство афганцев не было действительно ознакомлено с этими современными элементами и они не были действительно ими приняты, всякие новые идеи обречены на провал.

Фотографии афганских женщин, сделанные в Кабуле в 1950-х и 1960-х годахбольшинство из них с непокрытой головой и одетые в западную одежду,-студенты или молодые интеллектуалы, позирующие на своей современной работе, вероятно вызовут удивление у тех, кто увидит их сегодня (как вызывали удивление и тогда), имея в виду то, что они так противоречат многому в нынешней реальности Афганистана. В ходе моего исследования я наткнулась на книгу, вышедшей в 1960 году, озаглавленную Афганистан: древняя земля с современным образом жизни, которая была полна похожими изображениями. Несмотря на то, что фотографии настоящие, они имеют мало общего с действительной жизнью большинства афганцев, как в прошлом, так и сегодня. В результате этого открытия логически возникает вопрос: где (или где было) место женщины в афганском обществе? Являются ли призывы к равенству полов еще одной химерой или ріuт desiderium (благопожеланием) западных людей, или оно является надежной основой для реальной новой стратегии в этом вопросе. Согласно первой леди Соединенных Штатов, Лауре Буш, война с терроризмом была «борьбой за права и достоинство женщин». ${ }^{26}$ Согласно социальному антропологу Лиле Абу-Лугход, «спасение афганских женщин» было частью оправдания интервенции США в октябре 2001 года. $^{27}$ Являются ли спрятанные под бурками женщины жертвами без достоинства, голоса и статуса в их обществе? Является ли бурка символом подавления? Или у нас ошибочные восприятия? В стране, объединенной в течении века под владычеством пуштунских королей в духе Пуштунвали, женщинам выделено скромное место, по крайней мере так выглядит снаружи. Как было указано, жизнь в афганском обществе разделена не только между мужчинами и женщинами, но и между публичной и частной сферой. Женщины традиционно принадлежат последней. В рамках их легитимного пространства «они могут упражнять влияние и даже настоящую власть, иногда как средство сопротивления». ${ }^{28}$

В соответствии с исламским законом и практикой, женщины тоже могут владеть собственностью, хотя некоторые племенные правила лишают женщин права

26 James Gerstenzang and Lisa Getter, "Laura Bush Addresses State of Afghan Women," Los Angeles Times (18 November, 2001); доступно на http://articles.latimes.com/2001/nov/18/news/ $\mathrm{mn}-5602$.

27 Nermeen Shaikh, Interview with Lila Abu-Lughod, Asia Source: "Why we can't save Afghan women," доступ 6 марта 2012, http://asiasociety.org/policy/social-issues/women-and-gender/ why-we-cant-save-afghanwomen.

28 Centlivres and Centlivres-Demont, "Afghan Women in the Turmoil of Modernity," 57. 
наследовать в пользу их родственников мужчин. Их имущество, которое редко состоит из земли, чаще магазины, транспортные средства или инструменты, управляется от их имени представителем мужчиной, вакилом, часто это старший брат или дядя. Эта практика, несомненно дискриминирующая и архаическая по западным стандартам равенства полов, встречалась в европейском обществе до конца 1960-х годов. Анализируя как освещается в западных средствах массовой информации афганское общество, Таиба Рахим отмечает, что «основная часть репортажей отмечена раздражающим комплексом превосходства, подразумевающего, что свобода, которой сегодня пользуются западные женщины, существовала всегда». ${ }^{29}$ Однако, эмансипация в нашем обществе была продолжительным процессом и большинство благоприятных перемен пришли снизу в результате существенных структурных сдвигов, расширения возможностей доступа к образованию, простой необходимости, практическим требованиям повседневной жизни и другим процессам развития общества.

Шаги к равноправию женщин часто воспринимаются как нарушение традиционного образа жизни. Уроки афганской истории указывают и на другие особенности этой страны, в частности на то, как решался вопрос равенства полов. Процесс эмансипации действительно имел место, но очень различным способом. Лидеры последнего столетия были слишком заняты формулированием и прокламированием своих взглядов на женщин и их место в обществе.

На самом деле мы можем утверждать, что улучшение статуса женщин происходило сверху - декретами и прецедентами, установленными женщинами королевских фамилий. Амир Абдул Рахман (1880-1901), известный как «Железный Амир», провел множество реформ для изменения традиционного статуса женщин, «идя против племенных обычаев заставлять женщину выходить замуж за брата ее умершего супруга, и утвердил право женщин наследовать собственность». ${ }^{30}$ Более существенные реформы последовали при правлении короля Амануллаха (19191929). Он попытался реформировать сегрегацию женщин в частной сфере и защищал допуск женщин в публичную жизнь, по крайней мере в минимальной степени. Королевы и сестры королей в этом смысле служили примером. Он провел некоторые социальные реформы, «в том числе новые правила ношения одежды, позволяющие женщинам в Кабуле ходить без паранджи». ${ }^{31}$ Его жена, королева Сорайя, была сфотографирована в вечернем платье без рукавов и без вуали во время их европейского тура, что дало определенный вклад в кампанию консерваторов против Амануллы-хана. Однако с тех пор отмена паранджи всегда воспринималась как признак освобождения женщин и западной современности.

29 Taiba Rahim, “An Identity of Strength: Personal Thoughts on Women in Afghanistan,” International Review of the Red Cross 847 (2002): 638.

30 Hassan K. Kakar, Government and Society in Afghanistan: The Reign of Abd al-Rahman Khan (Austin: University of Texas Press), 173.

31 Ludwig W. Adamec, Historical Dictionary of Afghanistan, $2^{\text {nd }}$ ed. (Lanham, MD: The Scarecrow Press, 1997), 36. 
Уже в 1920 году был намечен сдвиг в сторону женского образования и прав женщин. Школьное обучение девочек началось в 1921 году, когда была создана школа Есмат и в Турцию были отправлены несколько групп девушек для получения высшего образования. Но сельские районы и некоторые части городского населения чувствовали себя не связанными с королевскими реформами и отвергли их. Впоследствии эти реформы были сочтены нарушением их свобод и образа жизни и встретили сильное сопротивление. Восстание против управления Амануллы заставило его отменить большинство социальных реформ. Как отмечали социальные антропологи Пьер и Мишель Сентливрс, которые изучали афганское общество в течении десятилетий, «для многих афганцев эти меры были невыносимым нарушением социального и божественного порядка, заговором против фундаментальных представлений о мужской чести и божественных законах, в которых племенной кодекс и религиозное право тесно связаны». ${ }^{32}$ Следующие короли, Надир-шах (1923-1933) и Захир-шах (1933-1973), продолжили политику поддержки обучения и образования женщин, но при этом сохраняя их сегрегацию, таким образом примиряя высшее образование и пурду. Позже премьер-министр Дауд (1953-1963) навязал «добровольное» снятие паранджи.

Женщины кабульской элиты были единственными, которые не носили бурку или хотя бы вуаль в 1960-х и 1970-х, период, когда были сделаны эти ошеломляющие фотографии. Остальная часть женского населения Афганистана не оказала такую же поддержку этому «новшеству» и провинции реагировали еще более сдержано, как это происходит и сегодня. Когда Дауд-шах стал президентом Афганистана в 1973 году, он продолжил реформы, направленные на предоставление прав женщинам и их присутствие в судебной, образовательной, административной и политической сфере увеличилось. Но в очередной раз это не было результатом феминистского движения в Афганистане. Не было афганских суфражисток, агитирующих за расширение прав женщин; скорее прогресс для женщин был результатом политической программы человека у руля власти. Очень точно это было сформулировано в короткой статье Нэнси Дюпре: «они вышли из своих домов и сняли свои покрывала потому, что лидеры-мужчины по своей собственной воле приказали им сделать так». ${ }^{33}$ Волна освобождения достигла Кабула в 1970-х и реформы сопровождались определенной либерализацией обычаев. Девушки ходили в школы и в университеты без платков и даже можно было увидеть мини-юбки, особенно в Кабуле. Это было и стимулом и «побочным» продуктом конституции от 1977 года, написанной во времена республики, которая явным образом декларировала равенство прав и обязанностей мужчин и женщин. Несмотря на три десятилетия между 1950 и 1980, в течении которых условия для женщин улучшились, все еще существовала культурная пропасть между столицей и главными городами с одной стороны, и глубинкой с другой.

32 Centlivres and Centlivres-Demont, "Afghan Women in the Turmoil of Modernity," 66.

33 Nancy Hatch Dupree, The Women of Afghanistan (Islamabad: published by the Office of the U.N. Coordinator for Afghanistan, 1998), 5. 
Когда марксистский переворот в 1978 году затянулся и достиг интенсивности открытой войны, многие из элиты, в том числе и образованные женщины, эмигрировали. В целом, применение марксистко-ленинских идей к действительности в основном сельского и мусульманского Афганистана, вместе с идеями о равенстве в отношениях мужчин и женщин, не было воспринято положительно. Народнодемократическая партия Афганистана (НДПА) содействовала эмансипации женщин, и женщины, которые поддерживали режим, выходили с непокрытой головой или в маленьком платке. Однако, в тот же самый период, «образованные афганские женщины, не принимающие режим, часто носили вуаль; она была символом сопротивления против советского присутствия в Афганистане». ${ }^{34}$ Все режимы, каждый по своему, прокламировали свою приверженность правам женщин, включая и нынешнее правительство. Коммунисты хотели освободить их от патриархата и подчинения, моджахеды - спасти их от «безбожия и распущенности, введенных коммунистами, а талибы заявляют, что защищают их от отсутствия безопасности и от нападений во время режима моджахедов, от моральной деградации и от западного влияния». ${ }^{35}$

Закрытие образовательных институций для девушек и исключение женщин из общественной жизни привело к ситуации, когда только небольшому числу профессионалов-медиков было разрешено остаться на работе. После декрета талибов, обязывающего женщин носить бурку, они снова стали невидимой частью общества. За десятилетие после начала западной интервенции в ноябре 2001 года ситуация улучшилась до «нормальной» или, как говорят многие, «вернулась к прежнему». Афганская конституция от 2004 года снова гарантирует равные права для женщин. Опять открылись школы, по крайней мере в больших городах, и медицинские клиники и госпитали стали доступны женщинам, так же как и большинство академических институций. Женщины принимают участие в политической жизни и занимают публичные должности, несмотря на факт, что эти достижения часто являются только результатом существования обязательных квот для женщин. Женщин нанимают на работу, они могут ходить сами на рынок, использовать общественный транспорт и т.д. Были учреждены ключевые институции-такие как Министерство по делам женщин, Комиссия по защите прав человека, Национальная ассамблея,-—в которых женщины играют активную роль.

Однако бурка не исчезла с улиц афганских городов и сел. Является ли с западной точки зрения отказ от бурки равнозначным предоставлению прав женщинам? Является ли она сегодня символом мужского доминирования и угнетения женщин? Во всем многоцветии, что можно увидеть в разных регионах, бурка остается символом принадлежности как к Исламу, так и к Афганистану. Она приобрела и определенное культурное значение. По словам одной кабульской женщины, «она стала частью культуры. Мы не снимем ее просто потому, что Запад хочет этого». ${ }^{36}$

34 Centlivres and Centlivres-Demont, "Afghan Women in the Turmoil of Modernity," 89.

35 Там же, 92.

36 Там же, 91. 
Надо ли пересмотреть наше толкование бурки? Предположение, что только необразованные и угнетенные женщины носят бурку, может быть весьма распространенным в западных средствах массовой информации. В действительности бурка или чадра считается городской одеждой. В сельских районах ношение такой длинной одежды было бы очень непрактично при выполнении ежедневных сельскохозяйственных и домашних работ. При переезде в городские районы или при переезде из сельской местности в город, бурка является первой вещью, которую спешит купить женщина. Она дает ей анонимность и свободу посещать общественные места, удобство смотреть на других, оставаясь невидимой. По словам Пьера Сентивреса, «она символизирует роли, неоднозначные и дополняющие друг друга: слабость и защиту женщин от оскорбления взглядом, слабость и защиту мужчин от опасного блеска женского лица». ${ }^{37}$

Большинство афганских служащих-женщин, с которыми я работала, после рабочего дня в офисе надевали бурку. С небольшими исключениями, они использовали ее во время пребывания в общественном транспорте или когда посещали незнакомые им районы города. Степень, в которой они считались с другими социальными кодексами поведения, такими как личный выбор, смелость, религиозные взгляды их семей, так же как и степень знакомства с окружением, все это влияло на то, как и когда женщина предпочитает носить бурку. Ни одна из них не была необразованной. Все они были образованными, владели как минимум двумя языками и в некоторых случаях являлись основным кормильцем семьи. Они, несомненно, были прекрасным примером молодых, образованных, экономически независимых афганских женщин. То, что бурка давала им, это ощущение безопасности или защищенности во времена растущей небезопасности в стране. По той же причине бурку использовали многие женщины, сотрудники из международного персонала, работающие по всему Афганистану, которые часто, в зависимости от места службы и расположения, покупали эту типично афганскую одежду как дополнительное средство для обеспечения безопасности и защиты, широко известное среди экспатриантов как «аварийная бурка».

Антрополог Хана Папанек, которая проводила свои исследования в Пакистане, называла бурку формой «портативного уединения», и Лила Абу-Лугод, другой западный антрополог, работавшая на Ближнем Востоке и в Афганистане, определяет их как «подвижные дома». Она описывает их как «символ, который дает женщинам свободу передвигаться в общественных местах и среди незнакомых мужчин в сообществах, в которых респектабельность и защищенность женщин зависит от их ассоциированности с их семьями и домами, являющимися центром семейной жизни. Многие женщины по всему мусульманскому миру, которые надевают разных форм покрывала, считают, что это их выбор». ${ }^{38}$ Она так же подчеркивала, что

37 Pierre Centlivres, "Bouddha masque, femme voillée," в Points de vue. Pour Philippe Junoud, под ред. Danielle Chaperon, Philippe Kaenel (Paris: L'Harmattan, 2002), 339-55.

38 Nermeen Shaikh, "Why We Can't Save Afghan Women," interview with Lila Abu-Lughod, Asiasociety.org (accessed on 3 March 2012); available at http://asiasociety.org/policy/socialissues/women-and-gender/why-we-cant-save-afghan-women?page=0,0. 
в гуманитарных операциях, проводимых в Афганистане, есть риторические элементы миссионерского характера и идея «спасения» афганских женщин укрепляет чувство превосходства западной модели свободы женщин. Этот факт-что афганские женщины могут хотеть нечто отличное от того, что мы желаем для нихнадо признать и учитывать. Традиции, история и религия развивались в их стране по другому, чем на Западе, но все-таки не в полной изоляции; скорее, эта эволюция является результатом взаимосвязей с другими мирами, культурами и влияниями. Однако, основной идеал, который западные люди называют «свободой», может не быть на самом верху их шкалы ценностей, или по крайней мере не в той форме, как мы его понимаем и применяем на Западе. Цивилизационная миссия, одна из основных задач либерального порядка, может быть ненужной в этом случае. В контексте растущей небезопасности, распространяющегося фундаментализма и отрицания ценностей, пропагандируемых или навязываемых иностранцами, будущее афганских женщин часто зависит от моделей сопротивления, идущих из их прошлого.

\section{Политические структуры}

\section{Сильный слабый Президент}

Эта часть, как и предыдущая, сфокусирована на двух примерах политических структур, присутствующих в Афганистане, и их сложных отношениях в контексте племенного Афганистана. Сначала, на примере роли президента, мы сможем продемонстрировать, как существующие основные политические структуры играют существенную роль в государстве и как их взаимодействие с другими факторами оказывает влияние на политический процесс. Часто ученые анализируют власть в Афганистане, обращая особое внимание на связи между племенами и государством. И государство, и племена характеризуются четкими и ясно определенными структурами. Что, однако, неясно, это насколько симбиотичными они являются (или не являются), и какие связи существуют между законами, племенными традициями, персональной харизмой или патронажем. Приводит ли сочетание этих факторов к желаемому успеху, или они создают больше затруднений, чем это считалось первоначально? Как это взаимодействие отражается на реальном управлении, представленным наивысшим политическим постом в стране и какую роль оно играет в стабилизации Афганистана?

Политическая архитектура Исламской Республики Афганистан закреплена в Конституции, которая была разработана Афганской конституционной комиссией, получившей мандат в результате Боннского соглашения и утвержденной Большим советом Лойа Дюсира 4 января 2004 года. Было создано государство, которое должно было быть одновременно исламским и демократическим. Конституция от 2004 года обеспечила правовую основу для сильного президентства, национального собрания, состоящего из двух палат, и судебной системы. Конституция провозгласила равные права для женщин. В Преамбуле Конституции ислам объявляется священной религией, но Конституция гарантирует защиту и других вероиспо- 
веданий. Эти важные элементы, однако, потенциально содержат правовое несоответствие и показывают практический разрыв между писаным законодательством, с одной стороны, и традициями и практикой в Афганистане с другой. ${ }^{39}$

Глава III афганской конституции устанавливает сильный в правовом отношении пост Президента, который располагает большими правомочиями в отношении исполнительной и законодательной власти, как указано в статье 64 и многих последующих. На практике, однако, способность президента исполнять и применять свою власть в провинции-в основном посредством тридцати четырех губернаторов провинций и нескольких сотен районных суб-губернаторов-ограничена. В этой части мы исследуем, что является причиной такого несоответствия, какие трения существуют между президентом и другими элементами афганского руководства, и что подрывает этот сильный в правовом отношении пост.

В дополнении к пониманию правового базиса государства, фундаментальной задачей исследования афганской социальной и политической структуры является достижение понимания сложной композиции афганского населения и отношений между этническими группами. И последний король, Захир-шах, и нынешний президент, Хамид Карзай, являются пуштунами. Поэтому подробное исследование племенных отношений пуштунов критически важно для анализа и раскрытия источника проблем, оказывающего влияние на высший политический эшелон. Учитывая естественные племенные связи, неясно, является ли нынешний президент лучшим возможным лидером для раздираемой войной страны, или его племенная принадлежность усугубляет некоторые традиционные враждебные отношения вне зависимости от его профессиональной или политической компетентности. В какой степени этнические и племенные отношения влияют на политическое развитие Афганистана и на потенциал стабильности, если «этнические вопросы являются критически важными для оценки последствий для будущей афганской социальной и политической стабильности» ${ }^{40}$

Пуштуны составляют самую большую этническую группу в Афганистане. Они являются преимущественно мусульманами-суннитами, придерживающимися к ханафийской школе юриспруденции, которая считается самой либеральной среди четырех школ суннитского ислама. Как было уже показано в предыдущей части статьи, они подчиняются Пуштунвали, всеобъемлющему кодексу поведения и образу жизни. Пуштуны были объектом большего числа академических исследований, чем все другие основные афганские этнические группы; поэтому о пуштунских обычаях и племенной структуре есть больше информации по сравнению с остальными группами. Сложная структура их общества варьирует в зависимости от региона. Географическая местность и условия имеют влияние на структуру власти в Афганистане - в равнинах на юге доминируют иерархические и автократи-

39 Полный текст Афганской Конституции 2004 года доступен на www.unhcr.org/refworld/ docid/404d8a594.html.

40 Thomas H. Johnson, “Afghanistan's Post-Taliban Transition: The State of State-building after War," Central Asia Survey 25:1-2 (March-June 2006): 7. 
ческие структуры, тогда как в областях с более сложным рельефом, в горах или приграничных районах, имеет место эгалитарный или более демократический социальный порядок. Пуштуны, живущие в более изолированных горных регионах, имеют менее жесткую социальную структуру, так как условия изоляции приводят к тому, что социальные группы в большей степени идентифицируют себя со своим непосредственным окружением и расположением, чем со своим племенным происхождением.

Афганский президент Хамид Карзай является пуштуном, рожденным на юге, в городе Кандагаре. Он ведет свой род от южной линии сарбанов, представленных племенным союзом Дуррани и сардаров из племени Попалзай клана Садозай (смотри Приложение). ${ }^{41}$ «С его основания в 1747 году Афганистан, за исключением нескольких коротких периодов, когда доминировали таджики, находился под управлением пуштунов сардаров из кланов Садозай и Мохамадзай, пока последний король Афганистана, Захир-шах, не был свергнут в августе 1973 года», как подтверждает в своей истории современного Афганистана Амин Саикал. ${ }^{42}$

Боннское соглашение возобновило эту тенденцию в 2001 году, когда Карзай был назначен главой Переходного правительства Афганистана. Несмотря на претензии на связь с длинной исторической цепочкой лидеров, южные сарбаны составляют очень маленький процент афганского населения и распределены в две родословные линии: Зирок (известные как Дуррани) и Панджпай. ${ }^{43}$ Далее обе группы делятся на девять племен, одним из которых является племя Попалзай. (Смотри в Приложении диаграмму пуштунских подгрупп и карту, показывающую их распределение.) «Отчуждение представителей племени Панджпай от национального правительства и их ограниченное политическое представительство в бывших королевских кругах из племени Дуррани может являться причиной того, что они имеют большее представительство в руководстве талибов, что, в свою очередь, является причиной их активного участия в восстании». ${ }^{44}$ Пуштунский племенной союз Гилзай, который составляет 20-25 процентов афганского населения, включая многие Кучи (пуштуны-номады), известны как «умелые воины и другие считают их наиболее воинственной частью пуштунов, а они воспринимают себя как самый сильный племенной союз и как настоящие воины пуштунского этноса». ${ }^{45}$ Племя Гилзай имеет длинную историю участия во внутреннем конфликте и всегда были на ножах с правителями из племени Дуррани. Их недовольство в конце концов привело к свержению коммунистами в 1978 году возглавляемого

41 Сардары являются потомками племенных вождей и афганских королей.

42 Amin Saikal, Ravan Farhadi, and Kirill Nourzhanov, Modern Afghanistan: History of Struggle and Survival (London: I. B. Tauris, 2006).

43 По разным источникам южные сарбаны составляют 11-16 процентов афганского населения.

44 "Putting it Together in Southern Afghanistan," Tribal Analyses Center (May 2009), 6; доступно на www.tribalanalysiscenter.com/Research-Completed.html.

45 Ralph H. Magnus and Eden Naby, Afghanistan: Mullah, Marx and Mujahid (Bouder, CO: Westview Press, 1998), 12. 
представителями племени Дуррани правительства. Именно они составляли значительную часть воюющих афганских сил в каждой войне против иностранного захватчика. Племя Хотак считается аристократией Гилзаев. В связи с этим важно отметить, что духовный лидер талибов мулла Мухаммад Омар происходит из племени Хотак.

Внутри племенного общества руководители, как правило, выбираются на основе персональной харизмы, характера, уважения и их сети патронажа. Лидеров, которые не оправдывают ожиданий племени, обычно смещают и заменяют их другими членами племени, чаще всего их соперниками. Когда дело касается посторонних, племенные лидеры обычно занимают прагматическую позицию, так как их власть в большой степени зависит от их способности обеспечить благосостояние соплеменников.

Отношение племенных лидеров к органам государственной власти, к международным и национальным должностным лицам часто воспринимается как проистекающее из их представлений о том, как их племя может получить выгоды от таких связей. Хамид Карзай, чья роль в афганской войне была незначительной, возглавил страну в результате международного выбора. Как пишет Александер Никол: «До его принятия как президента в качестве компромиссного выбора для осуществления руководства в переходном периоде, мало людей в Афганистане и за пределами Афганистана вообще слышали о нем. Он не может претендовать на признание ни среди афганцев не-пуштунов, ни среди племенно-неоднородных пуштунов». ${ }^{46}$ Президент Карзай известен как человек сострадательный, трудолюбивый, благочестивый мусульманин и патриот Афганистана, но он не обладает харизмой, характерной для лидеров среди афганцев. Он не может претендовать ни на законное королевское происхождение, ни служить объединяющей фигурой для пуштунских кланов. Но он несомненно является политиком - «важнее всего то, что он демонстрирует отличное умение использовать традиции афганской джирги и оставаться на самом верху афганского племенного саммита». ${ }^{47}$ Карзай чувствует себя неуютно, когда надо использовать военную силу, что отличает его от харизматических, мученически погибших командиров, таких как Абдул Хак и Ахмад Шах Масуд. Вероятно, они были бы гораздо более категоричны в отношениях с полевыми командирами и в процессе уменьшении зависимости Афганистана от иностранцев.

Процесс Боннских договоренностей под эгидой ООН свел вместе представительные группы в попытке достичь согласия и сформировать новую политическую архитектуру для Афганистана. Однако афганские лидеры сыграли незначительную роль в проектировании характера перехода от конфликта к «миру». На деле, ключевые решения в процессе перемен принимались другими. Несмотря на поддерж-

46 Alexander Nicoll, "The Road to Lisbon," в Afghanistan to 2015 and Веyond, под ред. Тобу Dodge and Nicholas Redman, Adelphi Series 425-26 (London: International Institute for Strategic Studies, 2012), 33.

47 Peter Tomsen, Wars on Afghanistan: Messianic Terrorism, Tribal Conflicts, and the Failure of Great Powers (New York: PublicAffairs, 2011), 641. 
ку США, политическое положение Карзая не было надежным до выборов в 2004 году. Питер Томсен, являющийся специальным представителем президента США Джорджа Г.У. Буша в Афганистане с 1989 по 1992, дает подробный отчет об этом событии в своей книге Войны Афганистана. В 2002 году предполагалось, что Лойа Джирга в Кабуле выберет временного президента, который возглавит страну до проведения первых свободных президентских выборов. 10 июня 2002 года 900 из 1500 делегатов собрались вместе возле собрания Лойа Джирга, чтобы поддержать в качестве переходного президента Захир Шаха вместо Карзая. Журналист спросил главного советника Шаха, Абдула Вали, будет ли бывший король играть руководящую роль в стране. Ответ Вали был, что «решение в руках афганского народа. Король будет следовать любому решению афганского народа». ${ }^{48}$ Эти события показывали, что избрание Карзая не является несомненным. Программа на следующий день, день выборов, была изменена, и за изменением последовало требование со стороны Залмая Халилзада, назначенным Джорджем У. Бушем посланником США в Афганистане с ноября 2003 по июнь 2005, к Вали, чтобы «Захир Шах прочитал заявление перед средствами массовой информации, подготовленное штабом Карзая, в котором он отрицает, что является кандидатом на руководство переходом». ${ }^{49}$ Выпуск новостей с заявлением короля на пресс-конференции, созванной в тот же день, транслировался в средствах массовой информации в стране и за границей, а заявление было предоставлено делегатам в письменном виде. Настроение в ходе конференции, понятно, было омрачено новостью. Через несколько дней делегаты формально выбрали Хамида Карзая. Позже делегаты «жаловались, что не имели возможности выбрать руководителя, которого хотели. Грубо вмешиваясь в процесс выбора руководителей Афганистана на стороне Хамида Карзая, Соединенные Штаты лишили афганцев редкой возможности самим выбрать лидера, который не воспринимался бы как навязанный иностранцами». ${ }^{50}$ Поддержка США в 2002 году на Лойа Джирге укрепила политическую позицию Карзая на выборах в 2004 году, на которых он был переизбран президентом на следующие пять лет 55.4 процентами голосов. Возобновленный на выборах в 2009 году президентской мандат, однако, был весьма спорным и голосование с низкой долей участия в целом ассоциировались с обвинениями в подтасовке выборов.

Политическое выживание в Афганистане требует создания персональной сети патронажа, особенно с учетом того, что значительная часть страны контролируется полевыми командирами. Чтобы заручиться их поддержкой, «Карзай начал их кооптировать или покупать, предлагая им посты в кабинете и места губернаторов, как например Хаки Шах Мадарт, хитрый маг, известный в истории Афганистана тем, что манипулировал другими, обещая им прибыльные позиции. Так некоторые

$\begin{array}{ll}48 & \text { Там же, } 641 . \\ 49 & \text { Там же, 642. } \\ 50 & \text { Там же, 642. }\end{array}$ 
афганцы в шутку называли президента». ${ }^{51}$ Лояльность и способности министров, начальников полиции и президентской администрации, набранных таким способом, остаются под вопросом. Они занимали эти посты не в ущерб своим личным делам. В результате представление о централизованном управлении остается сюрреалистическим за пределами столицы. Власть остается локализованной в руках ряда местных акторов. Из-за отсутствия региональной поддержки власть правительства в провинциях остается слабой. Региональные лидеры являются ключом к укреплению власти правительства, но у них нет ни обязанности, ни мотивации содействовать правительству.

В некоторых академических анализах Афганистана аргументируется точка зрения, что «не центральное правительство, а племена, особенно в сельских районах, исторически определили судьбу афганского общества и поэтому нуждаются в поддержке международного сообщества для того, чтобы ослабить повстанческие группы и их религиозную экстремистскую идеологию, и попытаться впоследствии сбалансировать афганское общество». ${ }^{52}$ Вместо того, чтобы обдумать как по-настоящему помочь регионам, международное сообщество сосредотачивает свои усилия на поддержку центрального правительства, несмотря на ограниченный обхват его власти и повторяющиеся случаи широкомасштабной коррупции. Последний скандал с раскрытием обширной финансовой коррупции в Банке Кабула вынудил президента принять решение об учреждении специальной прокуратуры и специального суда. Его решение пойти таким путем, а не обратиться к генеральному прокурору, чтобы он рассмотрел случай мошенничества в размере более чем на 900 миллионов долларов США и требование «выплатить все сомнительные долги в течении двух месяцев», предполагает наличие политических мотивов, стоящих за этим решением, особенно если учитывать связи семьи Карзая с этой финансовой институцией. ${ }^{53}$ Риск угрозы лишиться иностранной финансовой помощи затронет интересы всех обыкновенных граждан Афганистана и повлияет на проекты развития по всей стране, и все-таки Карзай не отреагировал на требования стран-доноров разобраться с коррупцией так, как они того ожидали. Как отметил один журналист: «Сомнения в его способности справиться с таким уровнем власти получили широкое распространение и подпитывались утечками информации из политических депеш посольства США в Кабуле и посла США Карла Айкенберри. В одном из докладов говорилось, что он [Карзай] находится в центре проблем правительства и отчаянно пытается установить правильный баланс между институциональным и традиционным управлением. Айкенберри даже сказал, что Карзай неспособен понять самые рудиментарные принципы государственного строительства». ${ }^{54}$ В 2008 году Трансперанси Интернешнл поставила Афганистан

51 Там же, 802.

52 Johnson, “Afghanistan's Post-Taliban Transition."

53 Emma Graham-Harrison, "Kabul Bank Scandal," The Guardian (U.K.) (4 April 2012); доступно на www.guardian.co.uk/world/2012/apr/04/kabul-bank-hamid-karzai-special-tribunal.

54 Toby Dodge and Nicholas Redman, ed., Afghanistan to 2015 and Beyond, Adelphi Series 425-26 (London: International Institute for Strategic Studies, 2012), 86. 
на 175 место из 180 стран в своем рейтинге Индекс восприятия коррупции. В 2009 году Афганистан находился на третьем месте с конца, за ним остались только Мьянма и Сомали. Последние три позиции не изменились и в рейтинге за 2010 год. ${ }^{55}$

Хамид Карзай столкнулся со сложной ситуацией - активный и кровавый мятеж, присутствие иностранных войск и ограниченные власть и контроль над территорией Афганистана. Зависимость страны от иностранных доноров и частые случаи коррупции на высоком уровне, вместе с частой критикой его должности со стороны его сторонников за границей, могут иметь негативное отражение на развитии страны. Его политические решения должны были бы определяться высшим интересом о благополучии Афганистана, но похоже, это не всегда так. Протекционизм и политические компромиссы с целью сгладить или прикрыть неблаговидные действия своей сети патронажа или родственников, не вызывают симпатию у его западных друзей и доноров и не производят положительного впечатления на афганцев. Необходимость смены на этом самом высоком политическом посту, или пересмотр политических приоритетов нынешним президентом, являются жизненно важными и разумными при текущих обстоятельствах.

\section{Движение «Талибан»: снова (не)популярно!}

На примере движения «Талибан» в этой части мы укажем на некоторые критически важные факты, связанные с движением, и их влияние и отношение к существующим афганским структурам. Для этого нам нужно вернуться назад и бросить еще один взгляд на социальный код Пуштунвали, на племенную систему пуштунов, а так же и на афганскую историю, с тем чтобы получить ясную картину текущей ситуации. Суммируя эти факты, мы сможем вывести некоторые логические заключения о том, как можно подорвать движение «Талибан» путем поддержки местных структур. Чтобы достичь желаемого положения в Афганистане, коалиционные силы должны нанести поражение мятежникам-талибам. Среди множества этнических групп, живущих в Афганистане, только пуштуны присутствуют в движении талибов в большой доле. Обобщение, что все (или почти все) пуштуны талибы, является большим заблуждением; однако верно, что «большинство мятежников-талибов пуштуны». ${ }^{56}$ Поэтому в этой связи ознакомление с контекстом культуры и общества пуштунов более чем необходимо.

Несмотря на то, что его режим потерпел поражение в 2001 году, движение «Талибан» не исчезло из ежедневной жизни многих афганцев. Наоборот, они [талибы] почти сразу же восстановились, начали перевооружаться и воскрешать заново свои структуры, используя убежища в соседнем Пакистане. В действительности, на большой части территории восточного и южного Афганистана движение

55 Transparency International Corruption Perception Index 2010; доступно на www.transparency.org/policy_research/surveys_indices/cpi/2010/results.

56 Ahmed Rashid, Taliban: Militant Islam, Oil and Fundamentalism in Central Asia (New Haven, CT: Yale University Press, 2001), 1. 
«Талибан» снова исполняет роль правительства, что укрепляет его легитимность и его власть. Талибы устанавливают «теневые» администрации и обеспечивают правосудие для местного населения, тогда как центральное правительство оказывается не в состоянии делать это.

Как было отмечено в предыдущей части, пуштуны гордые, свободные и независимые люди, которые не боятся использовать насилие в защиту своего образа жизни. Их законы и строгий кодекс поведения основываются на чувстве независимости, на справедливости и прощении, на гостеприимстве и толерантности, а так же на четырех основных личностных ценностях: чести, мести, свободе и рыцарстве. В целом, пуштуны больше уважают решение конфликтов путем группового консенсуса, чем навязыванием решений высшей властью. Серьезные вопросы выносятся на джиргу, совет, чьи решения имеют всю тяжесть закона, основанного на эгалитарной форме группового консенсуса. Сильное проявление эгалитаризма в социальных структурах пуштунов делает почти невозможным подчинить их военному командованию или дисциплине. По этой причине англичане не позволяли принимать их на службу в британские войска в Индии. Несмотря на факт, что «их считали умелыми воинами, они были ненадежны и часто дезертировали, как только пересекали границы своих исконных земель». 57 Эта историческая модель поведения в широком масштабе наблюдается и сегодня, и проблема дезертирования из афганской национальной армии или из афганской полиции, вероятнее всего, имеет объяснение в таком ракурсе. Однако пуштуны имеют совсем недостаточное представительство в афганских силах безопасности.

Но из этого стереотипа есть исключение: если пуштуны чувствуют внешнюю угрозу, на время они подчиняются военному авторитету, роль которого исполняется уважаемым религиозным лидером, муллой. Советская инвазия в 1979 году породила условия, которые привели к созданию движения «Талибан». «Движение «Талибан», в отличие от традиционной системы Пуштунвали, восприняло гораздо более новую и совершенно отличную социальную конструкцию - жесткую версию Ислама, известную как ваххабизм». ${ }^{58}$ Это движение, ведущее свое начало с конца восемнадцатого века на Аравийском полуострове, стремится к применению более чистого, более консервативного типа ислама, такого, какой исповедовали пророк Мохаммед и его первые последователи, и к применению более жесткой версии законов Шариата. До советского нашествия ваххабизм практически был неизвестен в Афганистане. После декабря 1979 года мусульмане со всего мира собрались, чтобы бороться с Советами, и саудовские боевики принесли ваххабитский вариант ислама в Афганистан. Как писал Ахмед Рашид, «финансированные правительством Саудовской Аравии, частными пожертвованиями и Соединенными Штатами, и контролируемые Директоратом межведомственной разведки Пакистана, эти

57 Johnson, “Afghanistan's Post-Taliban Transition,” 50.

58 Там же, 53. 
группы «священных воинов», или моджахеды, достигли успеха в окончательном вытеснении Советов из Афганистана. ${ }^{59}$

Перед лицом иностранного нашествия не только пуштуны, но и афганцы в целом, очевидно без проблем, временно ограничивают свою персональную автономию и подчиняются религиозным лидерам для ведения священной войны. Это был традиционный способ борьбы афганцев с захватчиками. На этот раз они делали это вместе с иностранными союзниками, которые постепенно увеличивали свое влияние на разные фракции пуштунского сопротивления. Духовный лидер талибов, мулла Омар, приобретал растущий авторитет и легитимность «в глазах своих последователей, как командир во время войны». ${ }^{60}$

Применение ваххабистских практик усиливалось с укреплением режима талибов. Публичные порки женщин, которые вышли из дома без сопровождения, не были редкостью, и не было необычным забить камнями женщину до смерти по обвинению в прелюбодеянии. Девушкам было запрещено посещать школу, мужчины были обязаны отрастить бороду, развлечения и музыка были запрещены. В особенности в противоречии с Пуштунвали было навязывание бесчисленных правил, ведущих к применению физических наказаний по отношению ко взрослым мужчинам и женщинам. Наоборот, этот кодекс, основанный на социальном консенсусе, принимает пуштунов как независимые личности, которые не следуют приказам другого человека. Но вариант Шариата, поддерживаемый талибами, проводился в жизнь религиозными лидерами через строгую иерархию и «частое применение смертного наказания за гомосексуальность, прелюбодеяния, потребление наркотиков и другие проступки». ${ }^{61}$ Эти практики были в остром противоречии с социальной структурой пуштунов, с их шкалой ценностей или культурными нормами. Первоначально добровольной и реципрокной системой, предназначенной для военных целей (изгнание вторгнувшейся силы) злоупотребили, навязав ее как постоянную всем афганцам. Талибы попытались завладеть традиционной афганской социальной структурой и заменить ее своим собственным конструктом с тем, чтобы сохранить власть над племенами для обеспечения базы поддержки и источника человеческих ресурсов для рекрутирования своих военных сил.

Они эксплуатировали (и продолжают эксплуатировать) традиционную концепцию обязанности защищать (нанавати) и требования гостеприимства (мелмастия), и использовали верность племенным связям, чтобы укрепить свой союз. Во-первых, занятие позиции законных защитников населения от иностранных оккупантов-в прошлом Советов, сейчас американцев и их союзников из НАТО,помогло им добиться добровольной поддержки. Во-вторых, они в состоянии заполнить вакуум власти вне обхвата центрального правительства, и они в состоянии предоставлять услуги, которые правительство предоставить не может. Мест-

59 Ahmed Rashid, Descent Into Chaos: The United State and the Failure of Nation Building in Pakistan, Afghanistan and Central Asia (New York: Penguin, 2008), 10.

60 Johnson, “Afghanistan's Post-Taliban Transition,” 63.

61 Robert D. Crews and Amid Tarzi, The Taliban and the Crisis of Afghanistan (Cambridge, MA: Harvard University Press, 2009), 135. 
ное население может поддаться, если у него нет альтернативы или нет сил противопоставить себя их власти. И последнее, но не по значению обстоятельство, это то, что талибы построили медресе, которые первоначально были учреждены для миллионов детей афганских беженцев, живущих в Пакистане, вблизи афганской границы. Сначала в медресе в течении года или двух «проводилась индоктринация многих тысяч молодых афганцев, а затем военная подготовка. После этого их посылали через границу воевать с армией интервентов». ${ }^{62}$ В некоторых местах даже сегодня, если родители желают послать своих сыновей в школу, чтобы они научились читать и писать, медресе может оказаться единственной возможностью. Предоставление обыкновенным пуштунам или любым афганцам возможности выбрать альтернативное решение выглядит как решение проблемы уменьшения легитимности талибов и успешного противодействия мятежу. Несмотря на тот факт, что талибы пользуются значительной общественной поддержкой, в их популярности есть элемент принуждения, если у людей нет реальной возможности противопоставить себя им. Зависимость талибов от поддержки на местах является и их силой, и их слабостью.

В одной из самых бедных в мире стране, в которой по некоторым оценкам национальный доход на душу населения за 2011 год составляет 1000 долларов США, большая часть которого в течении последних десяти лет обеспечивалась благодаря жизненно важной помощи иностранных доноров, «купить» местную поддержку не требует почти никаких усилий. ${ }^{63}$ Экономическое неравенство между столицей и другими городскими центрами, с одной стороны, и сельской глубинки, где живет большинство населения, с другой, все еще является очень большим. Легитимность талибов в качестве защитников против иностранных захватчиков исчерпается, если не будет никаких основательных жалоб или причин для вооруженной борьбы. Их функция в традиционном пуштунском обществе может исчезнуть. Для достижения этого можно использовать то обстоятельство, что в целом афганцы не одобряют талибский вариант законов Шариата. Поддержка и укрепление традиционного племенного процесса в Афганистане национальным правительством или международным сообществом через инвестирование в образование, строительство инфраструктуры и финансирование проектов экономического восстановления ослабят движение «Талибан» и позволят традиционным структурам самим справиться с ваххабитами, как они это делали с незваными гостями в течении сотен лет.

\section{Реконструкция или деконструкция}

Когда мыв вошли в Афганистан в 1979 году, люди тепло нас приветствовали. Ровно через год 40 прочентов населения нас ненавидело. Через пять лет нас ненавидело

62 Tomsen, Wars on Afghanistan, 198.

63 U.S. Central Intelligence Agency, The World Fact Book: Afghanistan; доступно на www.cia.gov/library/publications/the-world-factbook/geos/af.html. 
60 прочентов населении. И ко времени, когда нам предстояло уйти, нас ненавидело

90 проиентов. Наконеи мы осознали, что мы воюем с народом. ${ }^{64}$

Ген. лейт. Руслан С. Аушев, СССР

Желание афганцев жить без внешнего вмешательства является основным принципом Пуштунвали и других моральных кодексов, которые существуют в афганской культуре, и его происхождение лежит в историческом опыте Афганистана. Племенные и культурные альянсы прежде всего образуются между семьями, или племенами, или каумами, и только в последнюю очередь с правительством и то только в том случае, когда это отвечает интересам и потребностям племени. В большинстве человеческих сообществ безопасность и благополучие являются основным приоритетом групп и отдельных лиц на любом уровне, и Афганистан не исключение. В докладе Международного Валютного Фонда (МВФ) отмечается, что правительство Афганистана определило «три основных столпа восстановления: безопасность, управление и верховенство закона; социальное и экономическое развитие». ${ }^{65}$ Традиционными средствами, обеспечивающими безопасность, являются племенные вооруженные формирования лашкар и арбакай, существование которых зависит от одобрения и участия всех членов социальной единицы. Часто местное население относится с опаской и сомнением к защите, которая обеспечивается средствами вне традиционных социальных групп. Тщательный учет культурной среды, специфически афганских структур и тонких различий наверняка улучшит военные успехи в борьбе с мятежниками, а так же реализацию гражданских программ. В июне 2009 года генерал Стэнли Мак-Кристал при его назначении командующим сил США в Афганистане заявил, что «мы действовали способом, который отделял нас-физически и психологически-от людей, которых мы хотели защитить». После оценки ситуации в Афганистане и признания необходимости изменить стратегический подход, один из членов рабочей группы по пересмотру стратегии сказал, что «тип доктрины борьбы с мятежниками, о которой идет речь, предполагает такой уровень знаний о стране, какой я не имею о своем родном городе». ${ }^{66}$ Все это приводит нас не только к признанию факта сложности афганской реальности, но так же к признанию необходимости приспособить к ней методы реализации стратегии и подготовки членов международного сообщества, которые выполняют свою миссию в Афганистане.

Тема осведомленности о культуре является частью предварительной (до прибытия) программы подготовки различных военных формирований в центрах НАТО или в самом Афганистане. За принципы оперативной подготовки отвечает Объединенное командование НАТО по трансформации в Норфолке, штат Вирджиния. Оперативная подготовка затем осуществляется в подчиненных формированиях, в основном в Центре подготовки в Ставангере. Однако, ответственность за

64 Цитировано в Megan K. Stack, “The Other Afghan War,” Los Angeles Times (23 November 2008), http://articles.latimes.com/2008/nov/23/world/fg-aushev23.

65 International Monetary Fund, "Afghanistan: National Development Strategy: Executive Summary 2008-2013,” Report 08/153 (May 2008).

${ }^{66}$ Bob Woodward, Obama's Wars (New York: Simon \& Schuster, 2010), 150. 
подготовку курсов и их содержание лежит на отдельных нациях, участвующих в ISAF (Международные силы содействия безопасности). В этой связи нет сведений о трансфере знаний и лучших практиках между силами ISAF. Военные позаботились обеспечить служащих в стране основными инструкциями для поведения в мусульманской среде в форме карточки. Некоторые военнослужащие обеспечены упрощенными инструкциями для поведения конкретно в Афганистане, как это принято в вооруженных силах США и Бельгии. В отличии от этой практики, немецкий Бундесвер обеспечивает подготовку, в том числе и информацию о культуре, но не предоставляет упрощенные инструкции на этот счет на карточке, только правила применения вооруженной силы. Чтобы избежать или уменьшить непреднамеренное отчуждение от местного населения, настоятельно рекомендуется, чтобы весь персонал получал подготовку до отправки на место службы, в том числе включающую в себя информацию об афганской культуре. По общему признанию, существует большой разрыв между подготовкой офицеров и солдатконтрактников, в смысле продолжительности и уровне знаний, но все-таки серьезная основа уже есть. С другой стороны, есть место для дальнейших усовершенствований и улучшений подготовки. Исследования культуры и работу по темам, подобным теме этой статьи, можно проводить как часть подготовки, предшествующей отправке, с тем чтобы усилить ощущение об уникальной сложности афганских социальных структур, которые варьируют в конкурирующих этнических группах, племенах, религиях и географических границах.

Подготовка гражданских лиц, посылаемых для выполнения гуманитарных миссий в Афганистан, менее институционализирована и менее развита. Так же, как и в вооруженных силах, за подготовку отвечает каждое отдельное ведомство. ООН обеспечивает обязательную подготовку каждому должностному лицу с международным назначением из любого ведомства, которое является частью зоны безопасности ООН, до отправки этого лица на место работы в Афганистан. Этот онлайн курс расширенной подготовки по безопасности не имеет частей, посвященных культурной специфике Афганистана и относится только к мерам безопасности. Курс подготовки по безопасным и надежным подходам в полевой обстановке (БНППО), разработанный Колледжем персонала ООН, предназначен в основном для офицеров по безопасности из аффилиированных ведомств. Этот курс сочетает теоретическую работу с практическими упражнениями и симуляциями, но это не программа для международного персонала, работающего в местах с высокой степенью риска (или любых других местах с интенсивно сложными условиями), и он дает минимум информации о проблемах безопасности, связанными с культурным контекстом. Инструктаж, проводимый по прибытии на место работы служителями по безопасности международных гуманитарных организаций является недостаточным и неудовлетворительным в части культурных и политических обстоятельств. Независимо от факта, что должностная характеристика каждой гуманитарной вакансии содержит требования к культурной осведомленности кандидата, соответствие этой категории требований никогда не рассматривается и не проверяется ни на каком уровне. В интервью со старшим служителем Управления 
по гуманитарным вопросам (УГВ), которое является частью Секретариата $\mathrm{OOH}$, ответственной за осуществление связей между гуманитарными акторами на месте и основным ведомством для гражданско-военной координации, он подтвердил недостаточность культурологической подготовки международного персонала. Также он заявил, что «предшествующий опыт в стране с подобным [мусульманским] контекстом является преимуществом, но он не делает их автоматически чувствительными к реальности там [в Афганистане]». ${ }^{67}$ Он добавил, что «наши меры и правила безопасности мешают нам вести эффективный диалог с местными акторами, которые могли бы гарантировать нашу безопасность и доступ к отдаленным областям, если мы хотим достичь своих бенефициариев». Поэтому адаптация правил безопасности и их эффективности в различных областях страны должна стать еще одной задачей в ряду проблем для гуманитарного сообщества.

Ограничение свободы и скука, которые проистекают от ограничения возможностей передвижения из-за рисков безопасности, являются факторами, к которым не подготовлены ни гуманитарные работники, ни солдаты. Их индивидуальные возможности управлять своим поведением в условиях таких ограничений варьируют весьма значительно. Было бы весьма полезно использовать уже существующие исследования и высоко профессиональные и качественные тренировочные курсы, в которых применялись бы интердисциплинарные подходы коллективами ученых, практиков, военных и гражданских работников, и которые работали бы вместе для передачи и совместного использования знаний. В ходе этого исследования я наткнулась на несколько хорошо структурированных, содержательных материалов, и на уже разработанные практические программы подготовки, доступные для оперативного использования. Один из лучших примеров программы, которая дает понять сущность афганских этнических особенностей, религиозных, социальных норм, этикета и культуры, это программа, разработанная в Университете западной Флориды. ${ }^{68}$

Как было подчеркнуто в первой части этой статьи, чувство чести является высшей ценностью для афганцев - позор грозит исключением из общества. Это важный факт, который надо учитывать при проведении операций или в профессиональной среде при работе с афганцами. Если солдат насильно войдет в дом пуштуна, пуштун лишается чести. Если войдет на женскую половину дома и нарушит пурду, будут опозорены женщины этой семьи. Если пуштуну будет сделано замечание или его ошибки будут указаны публично в рабочей среде, он лишается чести и последствия могут быть опасными. Знание культурно-специфического этикета, языка тела, жестов и осведомленность о местных представлениях о нехватке времени и сроках, было бы, определенно, не только преимуществом, но и спасающим жизнь средством в такой среде. Даже очень качественная тренировочная программа не может подготовить нас ко всему разнообразию ситуаций, кото-

67 Интервью со старшим служителем УГВ, проведенное 2 марта 2012 года в офисе УГВ ООН, в Женеве.

68 Смотри http://uwf.edu/atcdev/Afghanistan/index.html. 
рые могут возникнуть в этом основанном на понятии чести обществе с кодексами поведения, чуждыми западным ценностям. Готовы ли мы иметь дело с пурдой и гендерным разделением в профессиональной рабочей среде? Или с требованием мужской части персонала удалить женщин из их рабочего процесса? Не является ли в таком контексте направление на работу в Афганистан женщин определенным неудобством? Профессор Пьер Сентливрес, этнограф с многолетним исследовательским опытом в Афганистане, предлагает ответ на эту проблему в терминах восприятия, но он не рассматривает практически проблемы, которые имеют место в ежедневных взаимодействиях: «Только иностранная женщина может входить и в женскую сферу, и в мир мужчин. В глазах мужчин иностранная женщина, прежде чем являться женщиной, является личностью, чей женский характер нейтрализуется ее качеством европейского гостя и ее независимым, мужским статусом и поведением. Таким образом, допускается ее присутствие в местах, куда их собственным женам, дочерям и сестрам не разрешается входить». ${ }^{69}$ И его наблюдения корректны, хотя уважение к иностранным женщинам не приходит автоматически. Скорее, это вопрос установления доверия и уверенности, и когда оно установлено, можно быть уверенным, что обе стороны его заслужили.

Равенство полов утверждено конституцией Афганистана и широко поддерживается международным сообществом, но у него есть конкретный афганский контекст. В конституции написано, что «граждане Афганистана-независимо от того, мужчины они, или женщины-имеют равные права и обязанности перед законом», и имеются особые положения, направленные на стимулирование доступа женщин к образованию и к управлению. Но традиционное исламское право третирует мужчин и женщин в определенных случаях по-разному и существующее в Афганистане законодательство сохраняет некоторые из этих отличий. «Если возникнет конфликт между международным законодательством [декларация о правах человека] и законодательством страны, конституция не указывает, кому принадлежит приоритет. Если у нас консервативная система правосудия-каковой она и является,- она будет интерпретировать законы консервативным образом», заявляет Ахмад Надери, член афганской Независимой комиссии по правам человека, в интервью The Los Angeles Times. ${ }^{70}$ Разные программы международных гуманитарных организаций или НПО, которые направлены на защиту женщин, ставших жертвами торговли людьми или домашнего насилия, сталкиваются с проблемами, связанными с бадал (местью), которой хочет семья жертвы. Если они сбегают и находят приют в гуманитарных организациях, считается, что они обесчестили семью и в соответствии с моральным кодексом Паштунвали оказываются приговорены к смертной казни. Наказание обязан исполнить отец, а если он не успеет, эта обязанность переходит к старшему наследнику мужского рода. Это обстоятель-

69 Centlivres and Centlivres-Demont, "Afghan Women in the Turmoil of Modernity," 54.

70 Sharon Otterman, "Afghanistan: The New Constitution," Council on Foreign Relations Backgrounder (6 January 2004); доступно на http://www.cfr.org/afghanistan/afghanistan-newconstitution/p7710. 
ство угрожает другим жертвам, живущим в приюте, и всем гуманитарным работникам, местным и иностранцам. Интернациональное сообщество не может гарантировать, как долго удастся поддерживать надежное охранное наблюдение приютов в будущем. Более конструктивным и менее опасным было бы его посредничество между семьями и общинами, а также поиск более устойчивых решений.

Население часто отвергает любые изменения, которые форсируются или навязываются управлением, вне зависимости от его легитимности, как показывает пример бурки. Усилия на эмансипацию отнимут время, и проекты, направленные на расширение прав женщин и их активного участия в жизни общества следует реализовать при высокой степени деликатности и с пониманием того, что это долгосрочные мероприятия. Образование определенно является лучшим и наиболее естественным путем поощрения и поддержки женщин и мужчин в Афганистане в процессе необратимых перемен. Вызовом остается рассмотрение эмансипации в более широком контексте, и особенно в том, что никогда не обсуждался международным сообществом: в возрастном. Многие молодые афганцы хотят стать более независимыми и принимать участие в процесс принятия решений, однако перед ними открыто очень мало дорог.

Первым шагом в проблеме изменения политических структур можно было бы считать тот, при котором функциональное управление стало бы более эффективным. Афганское правительство должно разрешить местным общинам, племенам и деревням выбирать своих лидеров уровня ниже районного посредством своего собственного социо-политического процесса. Все афганские этнические группы в сельских районах уже имеют общинное управление типа Шура или джирга на племенном уровне, принимающее решения по важным вопросам консенсусом. Улучшение этнических, социальных, экономических и политических структур и привязывание их к правительственным структурам является трудной долгосрочной целью, но она достижима, если этому будет способствовать международное сообщество в рамках своей перспективной стратегии. Однако, такую работу надо начинать на районном, а лучше, на еще более низком уровне. Такой шаг потребовал бы существенное изменение подхода самого афганского президента, так как он не только может номинировать свой кабинет и часть джирги, но также и государственных чиновников в регионах. Он должен действовать как мудрый, зрелый и опытный политик, высшим приоритетом которого является добро и благополучие его страны.

Несмотря на жалобы на ограниченные ресурсы, идущие в основном с афганской стороны, но иногда и от международных организаций и НПО, многие мероприятия и проекты планируются в таких масштабах, которое афганское общество не может эффективно ассимилировать ни в денежном, ни во временном измерении. Встраивание компонентов обучения в каждый проект и включение практической подготовки на месте как части нашего назначения, должно быть лейтмотивом наших миссий. Роберт Ламб пишет: «Управление в Афганистане в том смысле, в котором афганские и международные стратегии развития его дефинируют, не может стать «хорошим» как минимум в течении одного поколения, и 
усилия ускорить процесс-через конвенциональное строительство государства и демократизационные мероприятия в массовом масштабе-подпитывают коррупцию и подрывают перспективу на установление стабильности». ${ }^{71}$ Рэндалл Хоффман сходится с ним во мнении: «Ненужным риском и потенциально непреодолимым препятствием к достижению успеха в текущей стратегии США является чрезмерный упор на создание сильного центрального афганского правительства в надежде, что его растущая военная сила станет достаточной, чтобы нанести поражение отдельным щупальцам [Аль-Каиды] или Талибана. ${ }^{72}$

В этом эссе предлагается другой возможный вариант борьбы с мятежниками более конструктивным путем, с необходимым уважением к традиционным ценностям, представляемым кодексом Паштунвали и к естественным племенным связям. Усовершенствование местного управления через децентрализацию путем поддержки племенных или гибридных (формальных и неформальных) системпозволяющее изменения, видимые в маленьких, но реальных улучшениях жизни афганского общества и частного сектора,-вероятно, будет достаточным, чтобы избежать обращения большинства афганских общин к мятежникам для получения услуг или другой помощи, если они получат достаточную поддержку от национального правительства или международного сообщества. Хотя официальные политические заявления на высоком уровне призывают к поддержке центрального правительства, реальность на местах определяется более практическими потребностями, здравым смыслом и работой по реализации проектов. Военный компонент (представленный в основном Группами по восстановлению провинций) так же, как и гуманитарные работники, действующие на местах, работают в гораздо более тесном сотрудничестве с местными властями на племенном или провинциальном уровне, чем с центральным правительством. Местные лидеры участвуют в процессе восстановления, и джирга или Шура принимают участие, если возникает необходимость нанимать большое число местных рабочих или если разрабатываются или реализуются общинные проекты. Такой подход не только укрепляет авторитет джирги и традиционный социальный порядок, но и способствует укреплению доверия, а это делает местные общины менее восприимчивыми к влиянию талибов.

Конституциональная архитектура Афганистана создает зависимость низших уровней управления от центра практически во всех аспектах жизни, но центральное правительство, с его ограниченным влиянием вне столицы, не в состоянии в полной степени исполнять свои обязанности. Многие должностные лица из центрального управления не только не желают или не в состоянии нести полную ответственность за свой пост, но и не хотят потерять свои привилегии, престиж,

71 Robert D. Lamb, "Governance and Militancy in Afghanistan" (Washington, D.C.: Center for Strategic \& International Studies, May 2011), 2.

72 Maj. Randall S Hoffman, "The Way Ahead: Reclaiming the Pashtun Tribes through Joint Tribal Engagement," в Applications in Operational Culture, под ред. Paula Holmes-Eber, Patrice M. Scanlon, Andrea L. Hamlen (Quantico, VA: Marine Corps University Press, 2009), 84. 
влияние и право распределять покровительство. Несколько аналитиков, в их числе и Питер Томсен, пришли к выводу, что «на деле основным катализатором коррупции в Афганистане является чрезмерное международное внимание и бесконтрольные деньги, вливающиеся в страну в виде военных контрактов, дорогостоящих проектов оказания помощи, демократизационные и выборные реформы, создание технического потенциала, давление, оказываемое для формальной децентрализации, международные подрядчики и консультанты и другие общие элементы международного портфеля государственного строительства. Имея в виду нужды и проблемы Афганистана, эти усилия недостаточны; но в сравнении с тем, что Афганистан в действительности может переварить и усвоить, эти усилия чрезмерны и коррупционны. ${ }^{73}$

\section{Заключение}

Эта статья по необходимости ограничена в объеме и обхвате, и не является попыткой дать окончательный ответ на комплексные вопросы, с которыми сталкивается международное сообщество в Афганистане. Это скорее попытка привлечь внимание к культурным и политическим структурам, их связи с устоявшимися моделями поведения и с историей-глубоко укоренившимся факторам в племенном афганском обществе-с тем, чтобы высветить их важность, присутствие и функции. В идеальном случае эти факторы надо использовать как оперативные инструменты для достижения основных целей-стабилизации и восстановления этой разрываемой войной страны-и сделать так, чтобы наши проекты и стратегии были приняты теми людьми, которым они предназначены служить.

Как говорят критики, последние десятилетия в миростроительстве «показали тенденцию абстрагировать задачи строительства мира от их политического, культурного и исторического контекста. Эта тенденция стимулировала социально-инженерный подход к концепции строительства мира». ${ }^{74}$ Либеральный, сфокусированный на мире, подход считается «или фундаментально разрушительным, или незаконным, или и тем, и другим». ${ }^{75}$ Примеры его недостатков можно увидеть во многих странах по всему свету: фокус на краткосрочные, а не на долгосрочные цели; акцент на политические права и политическую повестку дня, включая скорые выборы вместо решительного экономического восстановления и социального примирения; поддержка центрального правительства, а не местных общин и традиционного местного руководства. В дополнении к этому, такой подход часто приводит к появлению социального и экономического неравенства и к навязыванию моральных критериев, которые часто противоречат традиционным правилам местного населения и «воспринимаются как 'чужие правила,' попирающие 'челове-

73 Lamb, "Governance and Militancy," 16.

74 Mats Berdal, Building Peace after War (London: International Institute for Strategic Studies, 2009), 19.

75 Roland Paris, "Saving Liberal Peacebuilding," Review of International Studies 36 (2010): 338. 
ческое достоинство'». ${ }^{76}$ Эти ошибки проявились в последних миссиях по строительству мира, и они продолжают повторяться без извлечения каких бы то ни было уроков.

Исторически афганские владетели руководствовались политической системой, которую в нынешних терминах можно определить как «федеральная и консультативная». Это можно объяснить тем фактом, что суннитская доктрина ханафи является неиерархической и децентрализованной, что мешало владетелям в двадцатом веке создать сильно централизованные государственные системы. Активным вмешательством и фаворизацией президентских амбиций Хамида Карзая в период первоначального выбора афганского руководства международное сообщество лишило афганцев возможности самим выбрать своего собственного руководителя. В ряду других негативов оно инициировало-вероятно, не желая того и непреднамеренно-патронажную связь, которую будет трудно прервать без последствий. Как показывает это исследование, существует огромное количество академических знаний и аналитической информации относительно различных факторов в контексте афганского общества, племен, политики, культуры и т.д. Поэтому утверждение, что нам не хватает достаточно знаний об Афганистане, просто неосновательно. Лучшее применение этих знаний и опыта путем взаимодействия с местным населением может привести к переоценке и более эффективному применению стратегий и целей, ведущих к желаемому конечному результату наших миссий.

Что нам мешает связать в единое целое теорию, знание и практику? На этот вопрос нет единственного ответа. Во-первых, политическая повестка дня международного сообщества и наши ценности несовместимы со многими ценностями, общими для афганского общества. Пропагандирование и финансирование «дружеской афганцам» стратегии, основанной на афганских ценностях, вряд ли будет популярным среди общественности Европы и США, особенно во время лишений и экономического кризиса. Во-вторых, возможное объяснение может предложить концепция солипсизма - решение проблемы, почему человеческое познание внешнего мира всегда остается ограниченным или невозможным. Попросту говоря, мы не можем видеть достаточно далеко за собственными пределами, чтобы по-настоящему познать окружающий мир в его собственных условиях. Однако, эта теория подвергалась многочисленной критике, и есть множество философских контра-аргументов. С моей точки зрения, сама сложность ситуации ведет к определенной степени неспособности или нежелания подойти к Афганистану одновременно с нескольких сторон и на нескольких уровнях.

Пристальное рассмотрение структур афганского общества в действительности может предложить подходящие варианты решения наиболее наболевших проблем: противодействие мятежу, укрепление политических структур и обеспечение экономической поддержки местным общинам. Несмотря на слова, подчеркивающие

76 William Bain, "In Praise of Folly: International Administration and Corruption of Humanity," International Affairs 82:3 (2006): 525-38. 
необходимость афганцам самим принять ответственность за свою безопасность, международное сообщество и гуманитарные организации должны сформировать свои программы таким образом, чтобы они поощряли самих афганцев находить афганские решения типично их, афганских, проблем. Активное участие афганцев при разработке проектов, которая осуществляется за океаном в США или в столицах Европы, должно стать неотъемлемой частью планирования и программирования. Долгосрочное обязательство преследовать изначальную цель-стабилизацию страны, но еще раз обдумав, как эта цель будет достигнута,-должно быть фундаментом любых дальнейших предпринимаемых шагов. Мы должны предоставить инструменты и обучение, которые позволят им действовать, а не подробные рецепты, что и как им делать.

Было объявлено, что уменьшение количества войск НАТО в Афганистане будет производиться при выполнении определенных условий, однако полный вывод войск должен закончиться к 2014 году. Большая ясность о деталях и о возможности дальнейшего присутствия и военного участия в Афганистане появится через некоторое время. Какими будут оперативные способности и эффективность афганских сил безопасности в 2014 году, трудно предсказать. При условии, что остается менее двух лет, некоторые из амбициозных планов НАТО по осуществлению перехода вероятно, останутся невыполненными. Будем надеяться, что гуманитарное присутствие будет продолжено и его помощь продлится на разумный период после 2014 года. Однако, в конечном итоге, только самим афганцам решать, в чем состоят их потребности и желания, и как, и в какой системе они желают продолжать жить. 


\section{Приложение: карта племен в Афганистане}
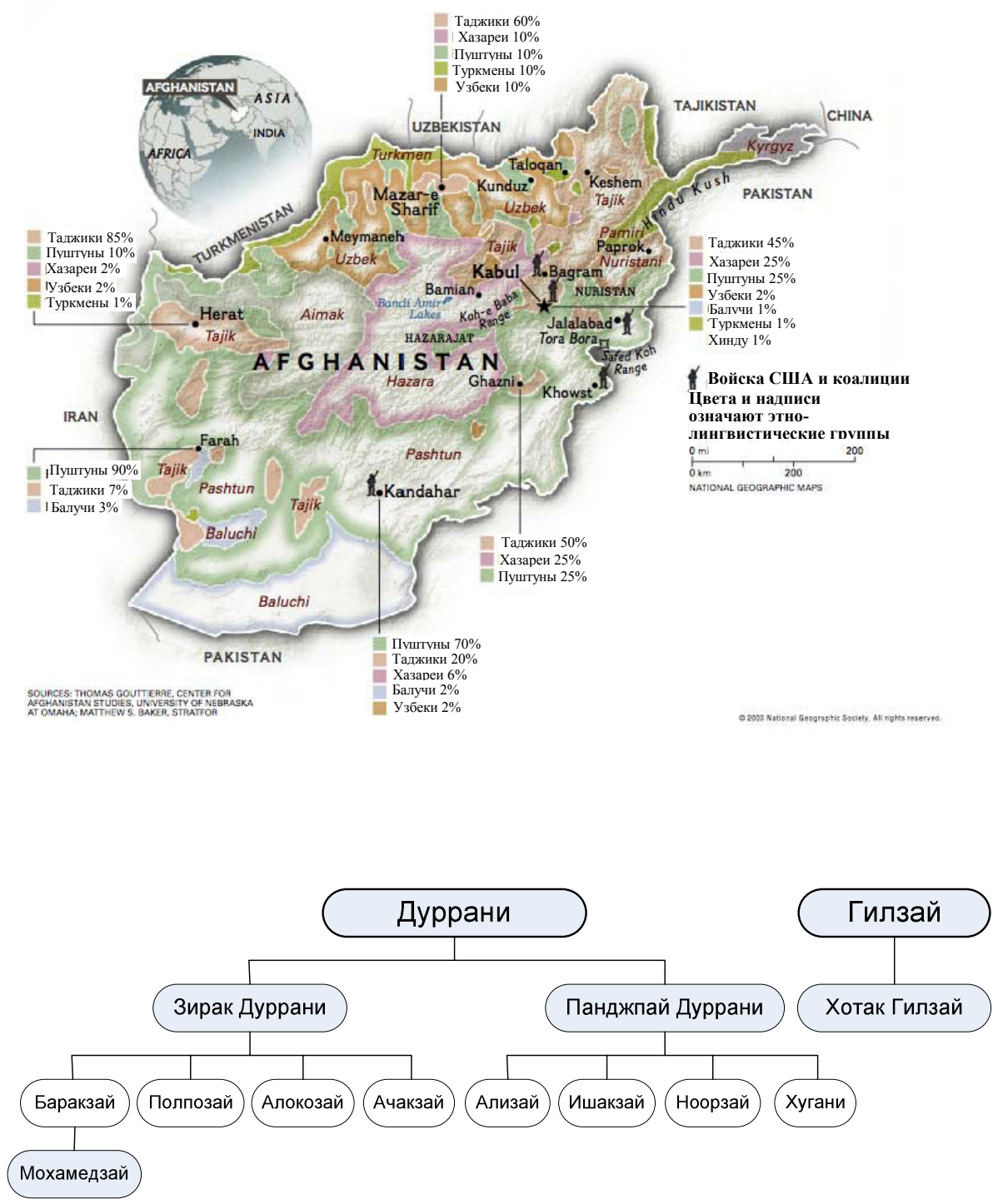

\section{Пуштунские племена}

Источник:Институт исследования войны; Carl Forsberg, The Taliban's Campaign for Kandahar (Washington, D.C.: Institute for the Study of War, November 2009). 


\section{Литература}

Adamec, Ludwig W.. Historical Dictionary of Afghanistan. 2nd ed. Lanham, MD: The Scare-crow Press, 1997.

Afghan Constitution., 2004.

Afghanistan to 2015 and Beyond In Adelphi Series. Vol. 425-26. International Institute for Strategic Studies, 2012.

Afghanistan: National Development Strategy: Executive Sum-mary 2008-2013. International Monetary Fund, 2008.

Ahmed, Akbar. Millennium and Charisma Among Pathans. A Critical Essay in Social Anthropology. London: Routledge and Kegan Paul, 1976.

Appelrouth, Scott A., and Laura Desfor Edles. Classical and Contemporary Theory. 2nd Edition ed. Thousand Oaks, CA: Pine Forge Press, 2012.

Bain, William. "In Praise of Folly: International Administration and Corruption of Humanity." International Affairs 82, no. 3 (2006): 525-38.

Barfield, Thomas J.. "Afghanistan's Ethnic Puzzle: Decentralizing Power Before the U.S: Withdrawal." Foreign Affairs 90, no. 5 (2011).

Barfield, Thomas J.. Hinterlands, Frontiers, Cities and States: Transactions and Identities. Yale University, 2007.

Barth, Frederik. Ethnic Groups and Boundaries: The Social Organization of Culture Difference. Boston : Little, Brown, 1969.

Berdal, Mats. Building Peace after War. London: International Institute for Strategic Studies, 2009.

Centlivres, Pierre, and Micheline Centlivres-Demont. Afghanistan on the Threshold of the 21st Century: Three Essays on Culture and Society. Princeton, NJ: Markus Wiener Publishers, 2010.

Centlivres, Pierre. Points de vue. Pour Philippe Junoud. Paris: L’Harmattan,, 2002.

Companion Encyclopedia of Anthropology. London: Routledge, 1994.

Crews, Robert D., and Amid Tarzi. The Taliban and the Crisis of Afghanistan. Cambridge, MA: Harvard University Press, 2009.

Dupree, Nancy Hatch. "Cultural Heritage and National Identity in Afghanistan." Third World Quarterly 23, no. 5 (2002): 977.

Dupree, Nancy Hatch. The Women of Afghanistan. Islamabad: Office of the U.N. Coordinator for Afghanistan, 1998. 
Geertz, Clifford. The Interpretation of Cultures. New York: Basic Books, 1973.

Gerstenzang, James, and Lisa Getter. "Laura Bush Addresses State of Afghan Women." Los Angeles Times (2001).

Giddens, Anthony. The Constitution of Society. Berkeley: University of California Press, 1984.

Graham-Harrison, Emma. "Kabul Bank Scandal." The Guardian (U.K.) (2012).

Hoffman, Maj. Randall S.. The Way Ahead: Reclaiming the Pashtun Tribes through Joint Tribal Engagement in Applications in Operational Culture. Quantico, VA: Marine Corps University Press, 2009.

Johnson, Thomas H., and Chris M. Mason. "No Sign Until the Burst of Fire." International Security 32, no. 4 (2008): 61.

Johnson, Thomas H.. "Afghanistan's Post-Taliban Transition: The State of Statebuilding after War." Central Asia Survey 25, no. 1-2 (2006): 7.

Kakar, Hassan K.. Government and Society in Afghanistan: The Reign of Abd alRahman Khan. Austin: University of Texas Press, 1979.

Kroeber, Alfred Louis, and Clyde Kluckholm. "Culture: A Critical Review of Concepts and Defi-nitions." Papers of the Peabody Museum of American Archaeology and Ethnology 47, no. 1 (1952).

Lamb, Robert D.. Governance and Militancy in Afghanistan. Washington, D.C: Center for Strategic \& International Studies, 2011.

Macionis, John J., and Ken Plummer. Sociology: A Global Introduction. Upper Saddle River, NJ: Pearson Education, 2010.

Magnus, Ralph H., and Eden Naby. Afghanistan: Mullah, Marx and Mujahid. Bouder, CO: Westview Press, 1998.

Merelman, Richard M.. Partial Vision: Culture and Politics in Britain, Canada and the United States. Madison: University of Wisconsin Press, 1991.

Mistdaq, Nabi. "Historic Perspective on Afghanistan, its People and Culture." Rayburn House Office Building, Washington D.C., 2009.

Nicoll, Alexander. The Road to Lisbon in Afghanistan to 2015 and Beyond In Adelphi Series 425-26. London: International Institute for Strategic Studies, 2012.

Otterman, Sharon. Afghanistan: The New Constitution. Council on Foreign Relations Back-grounder, 2004.

Palwasha, Kakar. Tribal Law of Pashtunwali and Women's Legislative Authority. Harvard Islamic Legal Studies Program, 2005. 
Paris, Roland. "Saving Liberal Peacebuilding." Review of International Studies 36 (2010): 338 .

Putting it Together in Southern Afghanistan. Tribal Analyses Center, 2009.

Rahim, Taiba. "An Identity of Strength: Personal Thoughts on Women in Afghanistan." Interna-tional Review of the Red Cross 847 (2002): 638.

Rashid, Ahmed. Taliban: Militant Islam, Oil and Fundamentalism in Central Asia. New Haven, CT: Yale University Press, 2001.

Rashidand, Ahmed. Descent Into Chaos: The United State and the Failure of Nation Building in Pakistan, Afghanistan and Central Asia. New York: Penguin,, 2008.

Saikal, Amin, Ravan Farhadi, and Kirill Nourzhanov. Modern Afghanistan: History of Struggle and Survival. London: I. B. Tauris, 2006.

Shaikh, Nermeen. Interview with Lila Abu-Lughod, Asia Source: “Why we can't save Afghan women., 2012.

Simon, Steven. "Can the Right War Be Won?" Foreign Affairs 88, no. 4 (2009): 30-37.

Spiro, Melford E.. Culture Theory: Essays on Mind, Self, and Emotion. Cambridge, UK: Cambridge University Press, 1984.

Stack, Megan K.. "The Other Afghan War." Los Angeles Times (2008).

The World Fact Book: Afghanistan. U.S. Central Intelligence Agency, 2001.

Tomsen, Peter. Wars on Afghanistan: Messianic Terrorism, Tribal Conflicts, and the Failure of Great Powers. New York : Public Affairs, 2011.

Transparency International Corruption Perception Index 2010., 2010.

Woodward, Bob. Obama's Wars. New York: Simon \& Schuster, 2010. 